\title{
Orbiting Carbon Observatory-2 (OCO-2) cloud screening algorithms: validation against collocated MODIS and CALIOP data
}

\author{
Thomas E. Taylor ${ }^{1}$, Christopher W. O'Dell ${ }^{1}$, Christian Frankenberg ${ }^{2,3}$, Philip T. Partain ${ }^{1}$, Heather Q. Cronk ${ }^{1}$, \\ Andrey Savtchenko ${ }^{4}$, Robert R. Nelson ${ }^{5}$, Emily J. Rosenthal ${ }^{5}$, Albert Y. Chang ${ }^{3}$, Brenden Fisher ${ }^{3}$, \\ Gregory B. Osterman ${ }^{3}$, Randy H. Pollock ${ }^{3}$, David Crisp ${ }^{3}$, Annmarie Eldering ${ }^{3}$, and Michael R. Gunson ${ }^{3}$ \\ ${ }^{1}$ Cooperative Institute for Research in the Atmosphere, Fort Collins, CO, USA \\ ${ }^{2}$ California Institute of Technology, Division of Geology and Planetary Sciences, Pasadena, CA, USA \\ ${ }^{3}$ Jet Propulsion Laboratory, California Institute of Technology, Pasadena, CA, USA \\ ${ }^{4}$ NASA Goddard Space Flight Center, Code 610.2/ADNET, Greenbelt, MA, USA \\ ${ }^{5}$ Department of Atmospheric Science, Colorado State Univ., Fort Collins, CO, USA
}

Correspondence to: Thomas E. Taylor (tommy.taylor@ colostate.edu)

Received: 22 October 2015 - Published in Atmos. Meas. Tech. Discuss.: 4 December 2015

Revised: 2 February 2016 - Accepted: 3 February 2016 - Published: 8 March 2016

\begin{abstract}
The objective of the National Aeronautics and Space Administration's (NASA) Orbiting Carbon Observatory-2 (OCO-2) mission is to retrieve the columnaveraged carbon dioxide $\left(\mathrm{CO}_{2}\right)$ dry air mole fraction $\left(\mathrm{X}_{\mathrm{CO}_{2}}\right)$ from satellite measurements of reflected sunlight in the near-infrared. These estimates can be biased by clouds and aerosols, i.e., contamination, within the instrument's field of view. Screening of the most contaminated soundings minimizes unnecessary calls to the computationally expensive Level 2 (L2) $\mathrm{X}_{\mathrm{CO}_{2}}$ retrieval algorithm. Hence, robust cloud screening methods have been an important focus of the OCO-2 algorithm development team. Two distinct, computationally inexpensive cloud screening algorithms have been developed for this application. The A-Band Preprocessor $(\mathrm{ABP})$ retrieves the surface pressure using measurements in the $0.76 \mu \mathrm{m} \mathrm{O}_{2} \mathrm{~A}$ band, neglecting scattering by clouds and aerosols, which introduce photon path-length differences that can cause large deviations between the expected and retrieved surface pressure. The Iterative Maximum A Posteriori (IMAP) Differential Optical Absorption Spectroscopy (DOAS) Preprocessor (IDP) retrieves independent estimates of the $\mathrm{CO}_{2}$ and $\mathrm{H}_{2} \mathrm{O}$ column abundances using observations taken at $1.61 \mu \mathrm{m}$ (weak $\mathrm{CO}_{2}$ band) and $2.06 \mu \mathrm{m}$ (strong $\mathrm{CO}_{2}$ band), while neglecting atmospheric scattering. The $\mathrm{CO}_{2}$ and $\mathrm{H}_{2} \mathrm{O}$ column abundances retrieved in these two spectral regions differ significantly in the presence of cloud and scattering aerosols. The combination of these two algo-
\end{abstract}

rithms, which are sensitive to different features in the spectra, provides the basis for cloud screening of the OCO-2 data set.

To validate the OCO-2 cloud screening approach, collocated measurements from NASA's Moderate Resolution Imaging Spectrometer (MODIS), aboard the Aqua platform, were compared to results from the two OCO-2 cloud screening algorithms. With tuning of algorithmic threshold parameters that allows for processing of $\simeq 20-25 \%$ of all OCO2 soundings, agreement between the OCO- 2 and MODIS cloud screening methods is found to be $\simeq 85 \%$ over four 16-day orbit repeat cycles in both the winter (December) and spring (April-May) for OCO-2 nadir-land, glint-land and glint-water observations.

No major, systematic, spatial or temporal dependencies were found, although slight differences in the seasonal data sets do exist and validation is more problematic with increasing solar zenith angle and when surfaces are covered in snow and ice and have complex topography. To further analyze the performance of the cloud screening algorithms, an initial comparison of OCO-2 observations was made to collocated measurements from the Cloud-Aerosol Lidar with Orthogonal Polarization (CALIOP) aboard the Cloud-Aerosol Lidar and Infrared Pathfinder Satellite Observations (CALIPSO). These comparisons highlight the strength of the OCO-2 cloud screening algorithms in identifying high, thin clouds but suggest some difficulty in identifying some clouds near 
the surface, even when the optical thicknesses are greater than 1 .

\section{Introduction}

NASA's OCO-2 satellite was launched on 2 July 2014 into a sun-synchronous orbit. After an initial on-orbit satellite bus checkout period, it was inserted into the $705 \mathrm{~km}$ Afternoon Constellation, known as the A-Train (L'Ecuyer and Jiang, 2010). From that orbit, it will collect measurements of reflected solar radiation in tandem with the other A-Train sensors such as MODIS-Aqua, CloudSat and Cloud-Aerosol Lidar with Orthogonal Polarization (CALIOP) (Xiong et al., 2009; Stephens et al., 2002; Winker et al., 2010). The OCO-2 instrument, described in detail in Crisp et al. (2008), contains three co-bore-sighted imaging spectrometers, fed by a common telescope. The light is dispersed via gratings to form two dimensional images of spectra onto a $1024 \times 1024$ pixel focal plane array. The three spectral bands, centered at $0.76 \mu \mathrm{m}$ $\left(\mathrm{O}_{2} \mathrm{~A}\right.$ band), $1.61 \mu \mathrm{m}$ (weak $\mathrm{CO}_{2}$ band) and $2.06 \mu \mathrm{m}$ (strong $\mathrm{CO}_{2}$ band), with resolving powers of 18000,21000 and 21000 , respectively, were chosen to provide high-precision retrievals of $\mathrm{X}_{\mathrm{CO}_{2}}$.

The orientation of the satellite bus rotates with latitude to align the optical elements at a constant orientation relative to the principle scattering plane defined by the earthsun-satellite geometry. With an integration time of $0.33 \mathrm{~s}$, each OCO-2 frame is approximately $2.3 \mathrm{~km}$ along-track. The cross-track width of the swath varies from $\simeq 0.1 \mathrm{~km}$, when the spectrometer slits are oriented along the orbit track, to $10.6 \mathrm{~km}$ at nadir, when the spectrometer slits are oriented perpendicular to the ground track. Cross-track frames are subdivided into eight equal footprints, each being approximately $1.3 \mathrm{~km}$ wide at nadir. Each footprint contains a single sounding comprised of spectra for all three OCO-2 bands. Further details of the instrument and satellite viewing modes can be found in Sects. 2.2 and 2.3 of Bösch et al. (2015).

For scenes containing significant amounts of cloud and/or aerosol, i.e., contamination, the OCO-2 Level 2 (L2) $\mathrm{X}_{\mathrm{CO}_{2}}$ retrieval algorithm fails to converge, thus wasting valuable processing time. More importantly, contamination at even modestly low optical thicknesses $(\lesssim 0.3)$ can introduce scene-dependent biases in the $\mathrm{X}_{\mathrm{CO}_{2}}$ (Butz et al., 2011; O'Dell et al., 2012; Guerlet et al., 2013), hindering the ability to accurately determine the sources and sinks on regional scales - the primary objective of OCO-2. It is therefore necessary to provide reliable cloud screening on all of the approximately 1 million OCO- 2 measurements collected each day. In this work the definition of optical thickness includes the contribution from aerosols, as well as from both ice and water clouds, except where noted. Therefore, for OCO-2, labeling a scene as cloudy indicates the detection of either cloud or aerosol or both.
The OCO-2 sampling approach was designed to mitigate the chances of introducing systematic biases in the retrieved $\mathrm{X}_{\mathrm{CO}_{2}}$ values (Bösch et al., 2006, 2011; Crisp et al., 2008). Two primary mitigation strategies related to cloud screening are the satellite's multiple observation modes and the small native footprint size of the instrument's field of view (FOV).

As discussed in Miller et al. (2007), nadir viewing observations, with the instrument bore sighted directly beneath the satellite orbit track, minimizes the FOV of individual footprints. However, nadir viewing yields low signal-to-noise ratios (SNRs) over water surfaces, which are very dark in the $\mathrm{CO}_{2}$ channels, making accurate $\mathrm{X}_{\mathrm{CO}_{2}}$ retrievals nearly impossible over much of the globe. Observations in glint viewing mode, with the bore sight oriented towards the point of specular reflection, maximizes the SNR but yields larger footprint sizes and longer atmospheric optical paths. This increases the likelihood of cloud contamination within the FOV.

The operational viewing strategy of OCO-2 in the early phase of the mission (September 2014 through June 2015) alternated between nadir-only and glint-only observations on successive 16-day ground track repeat cycles. However, on 2 July 2015 (the 1-year launch anniversary) the nominal sequence was modified to alternate between nadir and glint observations on successive orbits.

The OCO-2 spacecraft can also point the instrument boresight at a stationary surface location in the target observation mode, acquiring thousands of observations as it flies overhead. Target sites include validation targets, such as the Total Carbon Column Observing Network (TCCON) stations, which return precise $\mathrm{X}_{\mathrm{CO}_{2}}$ estimates using direct observations of the solar disk that can be compared to the OCO-2 $\mathrm{X}_{\mathrm{CO}_{2}}$ estimates to identify biases (Wunch et al., 2010, 2011). Anywhere from zero to three orbits each day are designated as a target orbit, with acquisition made only when the skies are predicted to be relatively clear and the local target solar zenith angle (SZA) is less than approximately $55^{\circ}$ (Wunch et al., 2016). However, the current validation study addresses only the global nadir and glint mode data.

Prior to the launch of OCO-2, the algorithm development team had the benefit of working with the Japanese Greenhouse Gases Observing Satellite (GOSAT) data set (Kuze et al., 2009; Yoshida et al., 2011). Analysis of the A-Band Preprocessor (ABP) cloud screening algorithm performance, similar to that presented here, was published in Taylor et al. (2012). That study concluded that the ABP, alone, yielded agreement with the MODIS cloud screening around $80 \%$ $(90 \%)$ of the time over land (ocean) surfaces. The Iterative Maximum A-Posteriori Differential Optical Absorption Spectroscopy Preprocessor (IDP) algorithm was not available at that time.

This study presents the first comparisons between OCO-2, MODIS-Aqua and CALIOP cloud screening results for a series of measurements collected during the first year of OCO2 operations. Because these sensors are all in the A-Train, 
this comparison yields far more collocated samples than the GOSAT comparison reported in (Taylor et al., 2012). The collocation data set for the MODIS comparison is comprised of four 16-day repeat cycles, two in nadir and two in glint viewing, over both a winter (December) and spring (AprilMay) time range (approximately 50 million soundings in total). For CALIOP, the comparison is performed on the May nadir-land observations. This provides a statistically robust global analysis of the OCO-2 cloud screening performance.

The work presented here is organized as follows. In Sect. 2, the two OCO-2 cloud screening algorithms are described and their performance on simulated data is summarized. Section 3 briefly discusses the OCO-2 B7 data used in this study and introduces the collocated MODIS and CALIOP products. Section 4 provides detailed analysis of the cloud screening validation procedure, including optimization of algorithm tuning and the direct comparison against both MODIS and CALIOP. Finally, summary conclusions are given in Sect. 5 .

\section{OCO-2 aerosol and cloud screening algorithms}

The OCO-2 ABP and the IDP algorithms are applied to the full OCO-2 data set as part of the operational data processing system. Since OCO- 2 collects almost 1 million soundings per day, both algorithms are made computationally efficient by neglecting atmospheric scattering by clouds and aerosols in the radiative transfer forward model. ABP does account for Rayleigh scattering by air molecules, which is non-negligible in the $\mathrm{O}_{2} \mathrm{~A}$ band, while IDP neglects all sources of scattering. By assuming clear-sky conditions, deviations of retrieved variables from expected values allow for the identification of scenes contaminated by cloud and aerosol. Brief descriptions of both algorithms are given below. In addition, we provide a detailed discussion of the merits of combining the two into a single cloud and aerosol filter and directly compare the performance on a set of simulated radiances.

\subsection{The ABP}

The ABP algorithm employs Bayesian optimal estimation (Rodgers, 2000) to retrieve surface pressure and surface albedo from high-resolution spectra in the $0.76 \mu \mathrm{m} \mathrm{O} \mathrm{O}_{2} \mathrm{~A}$ band, which contain a signature due to the absorption of reflected sunlight by oxygen molecules. Using some prior knowledge of the expected values, the retrieved parameters can be interpreted to provide information on cloud and aerosol contamination within the FOV of the satellite sensor.

The radiative transfer forward model assumes clear-sky conditions (molecular Rayleigh scattering only), such that differences between the modeled and measured radiances are often apparent when the scene contains cloud or aerosol. Estimates of the surface pressure from this algorithm, differenced against values from the nearest 3, 6, 9 or $12 \mathrm{~h}$ European Centre for Medium-Range Weather Forecasts (ECMWF) forecasts, interpolated to the observation, are calculated as $\Delta p_{\mathrm{s}, \text { cld }}=p_{\mathrm{s}}-p_{\mathrm{s}, \mathrm{a}}$. Here, the subscript $s$ refers to the surface, while $a$ refers to a priori. The value of $\Delta p_{\mathrm{s} \text {, cld, along }}$ with the surface albedo $(\alpha)$ and the $\chi^{2}$ goodness-of-fit statistic are used to identify changes in the expected optical path length, allowing scenes to be flagged as cloudy or clear.

The ABP algorithm was introduced and applied to early GOSAT data in Taylor et al. (2012), with further analysis performed on realistic GOSAT simulations given in O'Dell et al. (2012). More detail about this algorithm as applied to OCO-2 can be found in O'Dell et al. (2014). Simulations have demonstrated the ability of the ABP to reliably determine scenes contaminated with mid- or high-altitude clouds, although it sometimes has trouble detecting low level clouds, even when they are optically thick (O'Dell et al., 2012).

\subsection{The IDP}

The IDP algorithm performs independent, single-band nonscattering retrievals of the $\mathrm{CO}_{2}$ and $\mathrm{H}_{2} \mathrm{O}$ column abundances using radiances measured in the $1.61 \mu \mathrm{m}$ (weak) and $2.06 \mu \mathrm{m}$ (strong) $\mathrm{CO}_{2}$ bands. Ratios of the retrieved $\mathrm{CO}_{2}\left(R_{\mathrm{CO}_{2}}\right)$ and $\mathrm{H}_{2} \mathrm{O}\left(R_{\mathrm{H}_{2} \mathrm{O}}\right)$ column abundances are computed as

$R_{\mathrm{gas}}=\frac{\mathrm{VCD}_{\mathrm{gas}}^{\mathrm{W}}}{\mathrm{VCD}_{\mathrm{gas}}^{\mathrm{S}}}$,

where VCD represents the vertical column density of the retrieved gas $\left(\mathrm{CO}_{2}\right.$ or $\left.\mathrm{H}_{2} \mathrm{O}\right)$ in the weak and strong absorption bands.

Clouds and aerosols modify the optical path length in the two bands differently, producing column abundance ratios significantly different from unity (Frankenberg, 2014). There are two fundamental reasons why the ratio deviates from unity in the presence of scattering. First, for most terrestrial surfaces, albedos in the $1.6 \mu \mathrm{m}$ band are most often higher than at $2.0 \mu \mathrm{m}$. This yields a variable fractional contribution of scattered light to the OCO-2 radiances. Second, the 1.6 and $2.06 \mu \mathrm{m}$ band strengths are highly variable, resulting in different sensitivities to atmospheric scattering. If no scattering is assumed in the retrieval, a deviation from unity in the ratio thus indicates a substantial variation in the photon path-length (PPL) distribution between the two bands, while, in the absence of scattering, this ratio approaches unity. Details of the basic IDP retrieval algorithm mechanics can be found in Frankenberg et al. (2005). In contrast to the ABP, which is more sensitive to the altitude of the effective scattering layer, the IDP is more sensitive to spectrally dependent variations associated with the surface in the presence of clouds and aerosols or with the scattering properties of these particles, especially aerosols. 


\subsection{Combing ABP and IDP on simulated data}

Following the methodology described in O'Dell et al. (2012), the effectiveness of the combined ABP and IDP filters was tested using simulated OCO-2 and GOSAT measurements. These studies document observable differences in the cloud screening results between OCO-2 and GOSAT and quantify the relative reliability of the ABP for identifying high, thin clouds. They also provide predictions of the performance of the combined ABP and IDP algorithms.

A large set of simulations for both OCO-2 and GOSAT was created via the CSU orbit simulator model (O'Brien et al., 2009), which has realistic distributions of clouds, aerosols, surface types and viewing geometries for both missions. The OCO-2 orbit geometry was adopted for both instruments. The simulation data set consists of 96 orbits spanning 3 days in both June and December to cover a full range of solar zenith angles and viewing conditions. Soundings with a sub-satellite point over land were set to nadir viewing geometry, while those over water were set to view the specular glint spot. A temporal sampling rate of $1 \mathrm{~Hz}$ was used. Only the instrument model used to convolve the topof-atmosphere (TOA) reflected radiances differs between the two sets of simulations.

The major differences in the OCO-2 and GOSAT instruments are polarization sensitivity, spectral resolution, instrument line shape (ILS) and the noise models. Full details on the specific sensors and calibration procedures can be found in Crisp et al. (2008), O'Dell et al. (2011), Day et al. (2011), Rosenberg et al. (2016), Lee et al. (2016) and Bösch et al. (2015) for OCO-2 and Kuze et al. (2009) and Yoshida et al. (2010) for GOSAT.

O'Dell et al. (2012) found that $20-40 \%$ of thick, low water clouds or aerosol layers with total optical depth (TOD) $\gtrsim 1$ can be missed by the ABP for GOSAT simulated observations over land. The culprit appears to be a nearly complete cancellation of PPL shortening and lengthening, which can occur for certain combinations of cloud top pressure, cloud optical depth, solar zenith angle and the $\mathrm{O}_{2}$ A band surface albedo (e.g., see Sect. 2 of Taylor and O'Brien, 2009). This may be related to the "critical albedo" phenomenon described in Seidel and Popp (2012). In general, these cancellation effects can also occur in the weak and strong $\mathrm{CO}_{2}$ bands but are unlikely to occur in all three spectral regions simultaneously.

Panel (a) of Fig. 1 shows differences between the surface pressure retrieved by the $\mathrm{ABP}$ and the model a priori values, $\Delta p_{\mathrm{s} \text {, cld }}$, as a function of the model cloud plus aerosol optical depth (AOD) for $\simeq 30$ thousand synthetic soundings in nadir viewing mode over land in the month of June. The soundings are colored by the cloud relative height, defined as the height at which the partial-column TOD at $760 \mathrm{~nm}$ reaches the smaller of $50 \%$ of the TOD or unity, where the integration begins at the top of the atmosphere. This is a unitless quantity, as it is normalized by the surface pressure, i.e.,
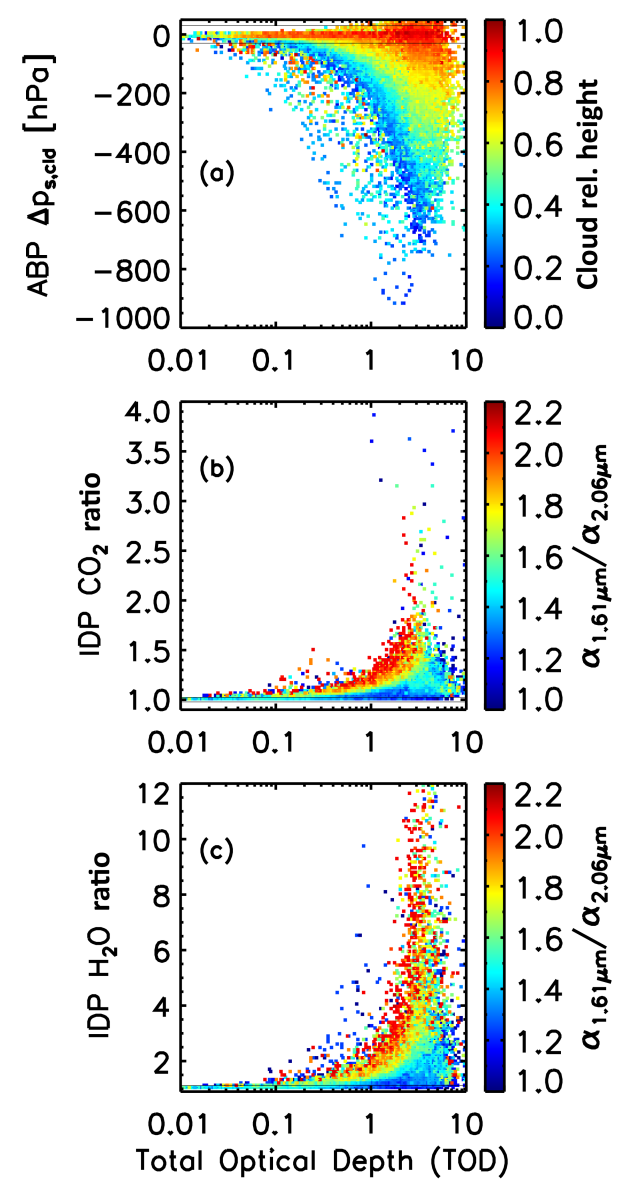

Figure 1. Scatter plots of (a) $\Delta p_{\mathrm{s} \text {, cld }}$, (b) $\mathrm{CO}_{2}$ ratio $\left(R_{\mathrm{CO}_{2}}\right)$ and (c) $\mathrm{H}_{2} \mathrm{O}$ ratio $\left(R_{\mathrm{H}_{2} \mathrm{O}}\right)$ versus the total optical depth for OCO-2 simulations over land for the month of June. In panel (a), each sounding is colored according to the cloud relative height (see text), while in panels (b) and (c), each sounding is colored according to the ratio of the 1.6 to the $2.0 \mu \mathrm{m}$ retrieved effective albedo. The horizontal black lines show the selected threshold values presented in Table 1.

$\mathrm{hPa} / \mathrm{hPa}$. Values near 0 (blue colors) represent high cloud or aerosol layers, while values near unity (red colors) represent low cloud or aerosol layers. The horizontal black lines in the figure show thresholds used to separate cloudy scenes from clear sky. The $\Delta p_{\mathrm{s} \text {, cld }}$ test is two sided; deviations from the ECMWF a priori, either high or low, will cause the scenes to be flagged as cloudy.

For the OCO-2 instrument model, the value of $\Delta p_{\mathrm{s} \text {, cld }}$ diverges from 0 at a lower TOD for the high clouds (blue colors) than it does for low clouds (red colors). This is an indicator of the ABP's ability to detect high, optically thin clouds due to strong PPL modification. However, the ABP has more difficulty identifying low clouds, even some that are optically thick, as seen by the large number of bright red data points with small $\Delta p_{\mathrm{s} \text {, cld }}$ at high TOD. This is due to their relatively small effect on PPLs. 
Results (not shown) were quantitatively similar for

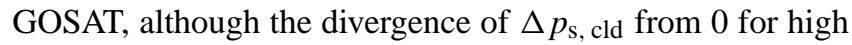
cloud occurs at higher values of TOD than it does for the OCO-2 instrument model. This suggests a lower sensitivity in the $\mathrm{O}_{2} \mathrm{~A}$ band, implying that the ABP is more sensitive to contamination by optically thin scattering layers for OCO-2 than for GOSAT. Further tests (not shown) indicate that this is not due to the difference in polarization response between the two instruments. Because their spectral ranges and resolutions are similar, the difference could be due to the OCO-2 noise model, which provides higher SNR in the absorption line cores relative to the continuum than does the spectrally uniform noise model of GOSAT. Another explanation for the improved OCO-2 sensitivity to thin clouds may be the much quicker fall off in the ILS wings, which should lead to deeper line cores despite the narrower full width at half maximum of the GOSAT ILS.

The IDP $R_{\mathrm{CO}_{2}}$ and $R_{\mathrm{H}_{2} \mathrm{O}}$ versus the TOD are shown in panels (b) and (c) of Fig. 1. Here, the color represents the ratio of the $1.61 \mu \mathrm{m}$ to the $2.06 \mu \mathrm{m}$ retrieved effective albedos, $R_{\alpha}=\alpha_{1.61 \mu \mathrm{m}} / \alpha_{2.06 \mu \mathrm{m}}$. In the absence of scattering the respective $R_{\mathrm{CO}_{2}}$ and $R_{\mathrm{H}_{2} \mathrm{O}}$ should converge to unity as the light path distributions in the strong and weak bands will be identical, irrespective of differences in surface albedos. For cases with larger TOD, however, the light path distributions will differ between the bands, resulting in ratios that deviate from 1 . We found that the ratios almost exclusively deviated in the positive direction, meaning that the PPL in the weak band was larger than in the strong band. This is most likely a consequence of generally lower surface albedos in the strong band as well as higher aerosol sensitivity owing to nearly saturated absorption lines.

As the values of $R_{\alpha}$ diverge from unity (move from blue to red colors in the plots), the IDP $R_{\mathrm{CO}_{2}}$ and $R_{\mathrm{H}_{2} \mathrm{O}}$ diverge from unity at lower values of the model TOD, thus allowing for more effective screening. In other words, when there are significant differences in the surface albedos of the two $\mathrm{CO}_{2}$ bands, the IDP has higher fidelity in identifying contamination by cloud and aerosol.

Figure 2 compares the fraction of soundings identified as clear by ABP only (blue), IDP only (green) and the combined set (black) for the OCO-2 June nadir-land simulated observations. The total number of scenes and the percent identified as clear are labeled on each panel for the three cloud screening combinations in the corresponding colors. Cloud screening yields are shown for (a) all scenes, (b) high clouds only and (c) low clouds. Here, high (low) cloud is defined as cases where $95 \%$ of the TOD resides in the top $40 \%$ (bottom $30 \%$ ) of the atmosphere. About 4 and $18 \%$ of the soundings were classified as high cloud and low cloud cases, respectively. The histogram, indicated by the gray shading, shows that there is a large fraction of simulated scenes with optical thickness $\simeq 3$. A similar feature is seen in the real CALIOP data, as will be displayed in Sect. 4.4. The authors currently have no explanation for this seemingly odd feature.

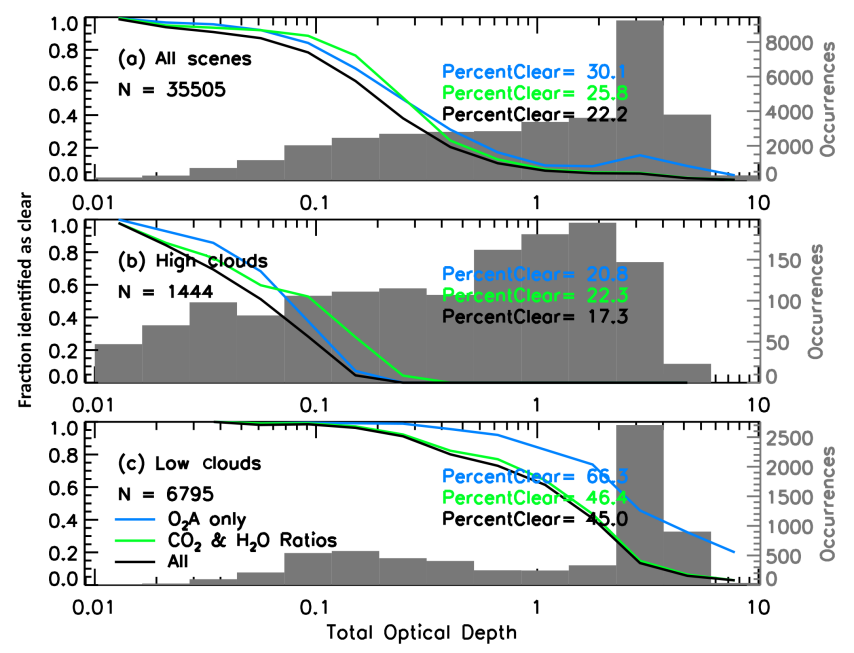

Figure 2. The fraction of simulated OCO-2 soundings identified as clear by the ABP screen alone (blue), by the $R_{\mathrm{CO}_{2}}$ plus $R_{\mathrm{H}_{2} \mathrm{O}}$ (green) and by all three filters combined (black), plotted as a function of the total cloud plus aerosol optical depth (TOD) at $760 \mathrm{~nm}$. The frequency histogram of the TOD is plotted in gray against the right ordinate. Panel (a) shows all cloud cases, while panel (b) shows only those scenes where $95 \%$ of the OD resides in the upper $40 \%$ of the atmosphere (i.e., high clouds) and panel (c) shows cases where $95 \%$ of the OD resides in the lowest $30 \%$ of the atmosphere (i.e., low clouds layers). Only the June nadir-land data are shown.

The values of the selected screening variables are provided

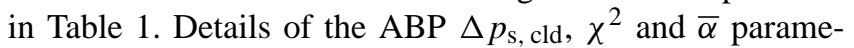
ters can be found in Sect. III.C. of Taylor et al. (2012). In summary, $\Delta p_{\mathrm{s} \text {, cld }}$ detects changes in the retrieved versus a priori surface pressure brought about by scattering-induced PPL modification. The multiplicative $\chi^{2}$ scale factor allows the dynamically calculated $\chi^{2}$ threshold to be scaled. Setting this parameter near unity indicates high confidence in the instrument calibration and spectroscopy, while very large values (say 20 or greater) effectively disable this test. Moderate values, like those used in this study, cause highly contaminated soundings to be screened but put most of the burden on the surface pressure check. The third ABP filter is a comparison of the retrieved surface albedo, averaged over the spectral band end points $(\bar{\alpha})$, against predefined lower and upper surface albedo thresholds. For all viewing configurations (nadirland, glint-land, glint-water), the lower threshold is set to 0 , while the upper threshold is set to unity for land surfaces and varies piecewise as a function of the glint angle for water surfaces. The glint angle, $\Theta$, is calculated directly from the solar and satellite observation geometries and indicates the angular difference between the sounding center point and the point of solar specular reflection.

The IDP $R_{\mathrm{CO}_{2}}$ and $R_{\mathrm{H}_{2} \mathrm{O}}$ center and half-width values, which are empirically determined, simply define the acceptable range of $R_{\mathrm{CO}_{2}}$ and $R_{\mathrm{H}_{2} \mathrm{O}}$. Soundings with calculated 
Table 1. Settings of the ABP and IDP cloud screening thresholds used for the OCO-2 and GOSAT simulated data sets discussed in Sect. 2.3 and the real OCO-2 data used in Sect. 4.2. Here, $\Theta$ represents the glint angle, as defined in the text.

\begin{tabular}{|c|c|c|c|c|c|}
\hline & $\begin{array}{l}\text { OCO-2 } \\
\text { simulated }\end{array}$ & $\begin{array}{l}\text { GOSAT } \\
\text { simulated }\end{array}$ & $\begin{array}{l}\text { OCO-2 } \\
\text { real } \\
\text { nadir-land }\end{array}$ & $\begin{array}{l}\text { OCO-2 } \\
\text { real } \\
\text { glint-land }\end{array}$ & $\begin{array}{l}\text { OCO-2 } \\
\text { real } \\
\text { glint-water }\end{array}$ \\
\hline$\Delta p_{\mathrm{s}, \text { cld }}(\mathrm{hPa})$ & 30.0 & 10.0 & 20.0 & 20.0 & 20.0 \\
\hline$\chi^{2}$ scale factor & 5.0 & 2.0 & 5.0 & 5.0 & 5.0 \\
\hline 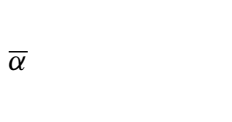 & $\begin{array}{c}\text { Same as } \\
\text { real OCO-2 }\end{array}$ & $\begin{array}{c}\text { See Table } 3 \text { in } \\
\text { Taylor et al. (2012) }\end{array}$ & $0.0<\bar{\alpha}<1.0$ & $0.0<\bar{\alpha}<1.0$ & $\begin{array}{c}0.0<\bar{\alpha}<1000 \text { for } 0.0<\Theta<3.0 \\
0.0<\bar{\alpha}<10 \text { for } 3.0<\Theta<30.0 \\
0.0<\bar{\alpha}<0.05 \text { for } \Theta>30.0\end{array}$ \\
\hline$R_{\mathrm{CO}_{2}}$ center & 1.0 & 1.0 & 0.99 & 0.99 & 0.98 \\
\hline$R_{\mathrm{CO}_{2}}$ half width & \pm 0.022 & \pm 0.015 & \pm 0.04 & \pm 0.04 & \pm 0.045 \\
\hline$R_{\mathrm{H}_{2} \mathrm{O}}$ center & 1.02 & 1.02 & 0.99 & 0.99 & 0.99 \\
\hline$R_{\mathrm{H}_{2} \mathrm{O}}$ half width & \pm 0.10 & \pm 0.10 & \pm 0.2 & \pm 0.2 & \pm 0.12 \\
\hline
\end{tabular}

$R_{\mathrm{CO}_{2}}$ and $R_{\mathrm{H}_{2} \mathrm{O}}$ that fall outside the allowed range are flagged as cloudy.

The top panel indicates general agreement between the two cloud screening algorithms in the all-scenes case. For example, when TOD $=0.25$ about $50 \%$ of the scenes are identified as clear by both ABP and IDP. The combination of $\mathrm{ABP}$ and IDP provides a more aggressive screening than a single filter, as seen by the lower fraction of scenes identified as clear at any given TOD. This indicates that ABP and IDP are not flagging identical soundings and are therefore complimentary. The curves in the plot indicate that all three cloud screening combinations (ABP-only, IDP-only and ABP + IDP) exhibit a smooth decay toward zero fraction passing with increasing TOD. The exception is a noticeable increase in the fraction identified as clear for $\mathrm{TOD} \simeq 3$, i.e., a misidentification of cloudy scenes as clear. As mentioned previously, the histogram (gray shading) indicates that there is a large number of scenes with TOD $\simeq 3$. This feature also appears in the real CALIOP data to be presented in Sect. 4.4. This odd feature in the data set is not currently understood.

Panel (b) of Fig. 2 indicates that at TOD $=0.25$, the percent identified as clear is 0,4 and $0 \%$ for the ABP, IDP and combined cloud screens, respectively. This is consistent with previous results (Taylor et al., 2012; O'Dell et al., 2012) that show the ABP filter to be extremely effective at screening high clouds. It also suggests that the IDP algorithm is reasonably effective at identifying high clouds.

In contrast, the lower panel of Fig. 2 shows that a large fraction of the optically thick, low clouds are not identified by the ABP and to a lesser extent by the IDP. For example, when $\mathrm{TOD}=1.0$, the clear-sky yields are 83, 64 and $61 \%$ for $\mathrm{ABP}$, IDP and combined cloud screens, respectively. This supports the findings for GOSAT presented in O'Dell et al. (2012) and confirms that ABP alone is unlikely to detect low clouds observed by OCO-2. However, combining the two filters yields a reduction of about a third of the number of low-altitude, cloud-contaminated scenes with $\mathrm{TOD}=1$, compared to us- ing the ABP alone. As shown in O'Dell et al. (2012), the remaining cloud-contaminated scenes do not exhibit PPL modifications in any band and therefore may yield unbiased $\mathrm{X}_{\mathrm{CO}_{2}}$ retrievals.

In summary, combining the ABP and IDP cloud filters in tandem yields a cloud and aerosol screener that is more effective at identifying scenes with both high- and low-altitude scattering material then either algorithm alone. Results from these two preprocessors are used in the sounding selection process for the OCO-2 $\mathrm{L} 2 \mathrm{X}_{\mathrm{CO}_{2}}$ retrieval algorithm.

\section{OCO-2, MODIS and CALIOP collocated data sets}

The A-Train is comprised of six satellites flying in tight formation that provide near-simultaneous observations from 14 sensors (L'Ecuyer and Jiang, 2010). The OCO-2 reference ground track (RGT) is identical to the CloudSat RGT, which is displaced $217.3 \mathrm{~km}$ east of the World Reference System (WRS)-2 track and has an Equator crossing time of 13:30 on the ascending node. This ground track was chosen so that, when OCO-2 is in the nadir observation mode, the surface footprints of the spectrometers are centered on the same ground track as the CloudSat radar and Cloud-Aerosol Lidar and Infrared Pathfinder Satellite Observations (CALIPSO) lidar.

Of particular interest for the validation of OCO-2 cloud screening are measurements made by MODIS-Aqua and CALIOP, which pass over an earth ground target approximately $7.5 \mathrm{~min}$ after OCO-2. The wide swath $(2330 \mathrm{~km}$ cross-track) of the MODIS instrument provides complete collocation with the narrow ground track $(<10 \mathrm{~km})$ of OCO2 . The MODIS cloud mask product is well characterized and easy to interpret (Ackerman et al., 1998, 2008), while the CALIOP cloud layered product provides unique information on the vertical distribution of clouds, albeit with a narrow ground track of only $\simeq 333 \mathrm{~m}$ native resolution (Winker et al., 2007; Vaughn et al., 2009). 
Table 2. Summary of OCO-2 B7 data set to which MODIS and CALIOP collocation were performed. Note that each OCO-2 frame contains eight footprints, i.e., eight soundings.

\begin{tabular}{lcccccc}
\hline Index & View mode & Start date & End date & NumDays & NumOrbits & NumFrames \\
\hline 1 & Glint & 01 Dec 2014 & 12 Dec 2014 & 12 & 153 & 1.35 million \\
2 & Nadir & 13 Dec 2014 & 28 Dec 2014 & 16 & 228 & 1.86 million \\
3 & Glint & 04 Apr 2015 & 18 Apr 2015 & 15 & 198 & 1.65 million \\
4 & Nadir & 11 May 2015 & 21 May 2015 & 11 & 147 & 1.13 million \\
\hline
\end{tabular}

A variety of MODIS-Aqua and CALIOP products, subsetted to the OCO-2 ground tracks, are being produced by the Cooperative Institute for Research in the Atmosphere (CIRA) Data Processing Center (DPC) at Colorado State University in collaboration with the A-Train Data Depot (ATDD) at the Goddard Earth Sciences Data and Information Services Center (GES-DISC). These products are being used for a variety of tasks such as spectral vicarious calibration of the instrument and detailed cloud and aerosol analysis. They will be made available to researchers upon request. The work presented here uses these collocated MODIS-Aqua and CALIOP products to provide validation of the OCO-2 cloud and aerosol screening for four sets of 16-day orbit repeat cycles in both nadir and glint viewing modes, as summarized in Table 2.

Figure 3 provides an example of the collocation of MODIS pixels to OCO-2 footprints. The OCO-2 spacecraft, and hence spectrometer slit, rotates as a function of latitude, producing frames that are nearly perpendicular (parallel) to the direction of motion near the equator (poles). Panel (a) provides spatial context of the narrow $(\simeq 10 \mathrm{~km})$ swath of OCO2 relative to part of the very wide $(\simeq 2330 \mathrm{~km})$ MODIS swath. This particular scene is across the Libyan desert in northern Africa on 13 August 2015 (orbit 5930), at which latitudes the OCO-2 slit is aligned non-perpendicular to the motion of the spacecraft, providing a swath width somewhat reduced from the $10 \mathrm{~km}$ maximum near the Equator. Panel (b) zooms in on a portion of panel (a) to show the relative size of the OCO-2 footprints against this typical scene of scattered clouds. In both panels, the individual OCO-2 footprints are labeled as cloudy (black) or clear (blue) based on the results from the combined ABP and IDP cloud screening algorithms.

Detailed explanation of the collocation technique is provided in the following section.

An analysis of the full OCO-2 data set spanning 6 September 2014 to 1 August 2015 (orbit numbers 958 to 5762) showed that, on average, slightly more than one third (36\%) of the nadir-land soundings pass the ABP operational cloud flag, i.e., are identified as clear, on a per-orbit basis. For nadir-water, glint-land and glint-water observations, the mean per-granule pass rates are $1.9,26.9$ and $23.0 \%$, respectively. The small yield for nadir-water soundings is predominately due to low signal-to-noise ratios, not just because

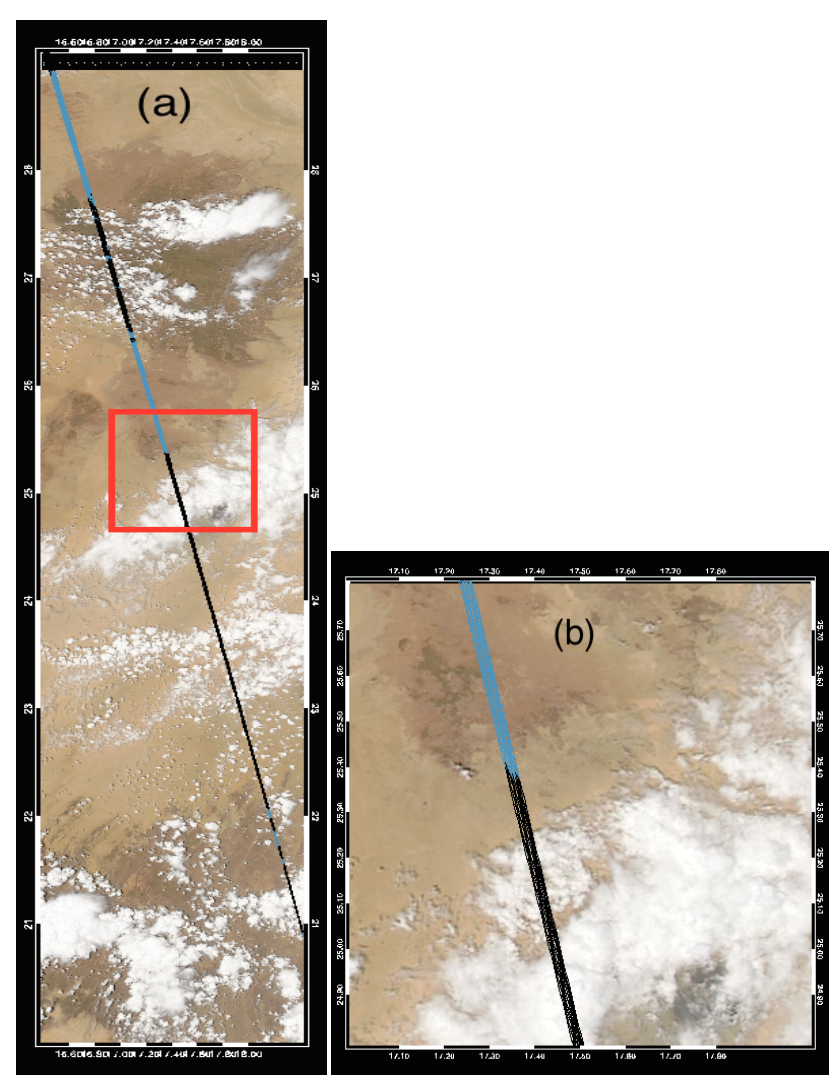

Figure 3. Demonstration of the collocation of MODIS to OCO-2 for orbit number 5930 (13 August 2015) in nadir viewing mode over central Africa. Panel (a) shows data spanning 20-29 $\mathrm{N}$ latitude and $16.4-18.5^{\circ}$ E longitude ( 450 frames in $\simeq 150 \mathrm{~s}$ ). Panel (b) shows a zoomed-in portion of the granule (the red box in Panel (a)) to reveal the relative width of an OCO-2 frame, which is comprised of eight cross-track footprints, each approximately $2 \mathrm{~km}$ by $2 \mathrm{~km}$, in relation to a typical scattered cloud deck observed by MODIS. The pixels are colored black (cloudy) or blue (clear) based on the combined ABP and IDP cloud screening algorithm results. The cloudy frames north of the visible cloud deck presumably contain subvisible clouds or aerosols.

they are cloudy. The few that do pass are both clear-sky and with geometry that allows high SNR values. These soundings make up a very small fraction of the full OCO-2 data set and will not be considered further in the current analysis. The ABP and IDP cloud screening algorithms used for the 
operational B7 data set are identifying approximately $20 \%$ of the 1 million daily soundings as clear. Of those soundings that are passed to the $\mathrm{L} 2$ retrieval algorithm, approximately $80 \%$ are sufficiently cloud free to yield $\mathrm{X}_{\mathrm{CO}_{2}}$ estimates that converge.

\subsection{Collocation methodology}

The ATDD generates collocated MODIS L1B and L2 atmospheric products for many of the satellites in the A-Train constellation using the algorithm described in Savtchenko et al. (2008). The main difference in the creation of the OCO-2 product relative to other A-Train sensors is the preparation of the reference track for ingest into the collocation algorithm. In the case of CloudSat, it is most convenient to use the twoline elements of the spacecraft to compute 15 min of CloudSat ground track for every MODIS 5 min granule. However, the OCO-2 flight modes make this simple approach unattainable. Instead, the geolocation and time information of the central OCO-2 footprint must be extracted from an OCO-2 L1B science granule. Based on that time, an "OpenSearch" request is formulated and sent to the MODIS Processing System (LAADS). Upon acquiring the corresponding MODIS 5 min granules (typically nine per OCO-2 granule), a work order is logged with the GES-DISC to push MODIS granules through the processing system. In most cases, part of the processing involves extrapolation of the OCO-2 track using the great arc model. The extrapolation is sufficiently accurate to extend the ground track of the OCO-2 footprint so that the resulting reference ground track fully transects the acquired MODIS granules. The resulting output are MODISlike 5 min HDF-EOS files that contain all the MODIS geolocation and science data for a given product within $\pm 50 \mathrm{~km}$ of the OCO-2 ground target.

Supplemental collocation of the OCO-2 soundings is performed at the DPC for MODIS L1A $1 \mathrm{~km}$ satellite and scene information, L1B half-kilometer radiances, 1 and $5 \mathrm{~km}$ cloud properties, the $10 \mathrm{~km}$ aerosol product as well as the CALIOP $1 \mathrm{~km}$ cloud layer product and the $5 \mathrm{~km}$ cloud and aerosol layered products. As is done at the ATDD, the date and time information is extracted from the OCO-2 L1B files to determine the corresponding MODIS and CALIOP granules. Then any product-specific preprocessing is performed and a pixel-by-pixel matching to the OCO-2 geolocation is done. Note that, in the case of MODIS products, the information from all $5 \mathrm{~min}$ granules corresponding to a given OCO-2 granule is output to a single file, such that there is a one-toone file correspondence between the original OCO-2 granule and the collocated MODIS products.

The resultant DPC output HDF-5 files contain geolocation and science data within $\pm 50 \mathrm{~km}$ of the OCO-2 ground target for MODIS and all geolocation and data for CALIOP. They also contain the geolocation and time information for OCO2 along with the $x$ and $y$ MODIS or CALIOP pixel location for each match-up, as well as information that allows users to trace back to the original MODIS and OCO-2 files including file names, subset start pixel index and collection label. This configuration allows user customization of the match-up process, such as distance-dependent pixel searching.

\subsection{MODIS cloud mask}

In this work, we define a hybrid MODIS cloud mask by combining the standard cloud mask (Ackerman et al., 1998; Frey et al., 2008) with the $1.38 \mu \mathrm{m}$ cirrus reflectance value (Gao et al., 2002), both contained in the MYD06 cloud product. This follows the procedure first described in Taylor et al. (2012). Each OCO-2 footprint, i.e., a scene, is assigned a reference state of either clear or cloudy based on the following MODIS cloud criteria. First, a subset is formed of all $1 \mathrm{~km}$ MODIS pixels with center latitude and longitudes falling within $2 \mathrm{~km}$ of the center latitude and longitude of an OCO-2 footprint. All scenes in which all of the MODIS pixels are labeled as confident or probably clear and with cirrus reflectance, $\mathcal{R}$, less than 0.01 , are defined as clear sky. If either of these conditions are violated, then the reference state of the scene is considered to be cloudy. We limit the analysis to MODIS pixels with viewing zenith angle $<30^{\circ}$ to avoid oblique lines of sight which can introduce errors (Maddux et al., 2010). No limit is placed on the SZA.

There is a temporal discrepancy between the overpass time of OCO-2 and MODIS of about $7.5 \mathrm{~min}$, during which the geometrical and optical properties of clouds are subject to small changes and/or drifting in or out of the scene. However, errors in the validation procedure are mitigated by enforcing the $2 \mathrm{~km}$ radial search $\left(\simeq 12.5 \mathrm{~km}^{2}\right)$ when matching MODIS pixels to the OCO-2 footprints. This conservative search requirement has the added benefit of mitigating sub-FOV cloud effects, which the ABP has been shown to have difficulty identifying via simulations created using a three dimensional radiative transfer model (Merrelli et al., 2015). The effect was shown to lead to biases of up to several parts per million in $\mathrm{X}_{\mathrm{CO}_{2}}$, dependent on the cloud size, surface albedo and illumination geometry, for tropospheric liquid water clouds.

The search criteria produces about 10 matching MODIS pixels per OCO-2 sounding. Tests were performed to ensure that the agreement between OCO-2 and MODIS cloud flags are not overly sensitive to the choice of the search radius, the cirrus reflectance or the sensor zenith angle.

Using the custom cloud mask described above, the MODIS cloudy-sky fraction was calculated from the collocated data set for the four 16-day repeat cycles used in this analysis. Figure 4 presents the results for the December and April-May data sets. The soundings are binned in $4^{\circ}$ by $4^{\circ}$ lat/long boxes, revealing both the total global extent of the analyzed data set as well as the large spatially coherent cloudy and clear areas. Extensive portions of the globe, especially the higher latitudes, are cloud covered a large fraction of the time $(>80 \%)$, while the Sahara and other dry land regions have low cloud fraction. In general, the subtropical 

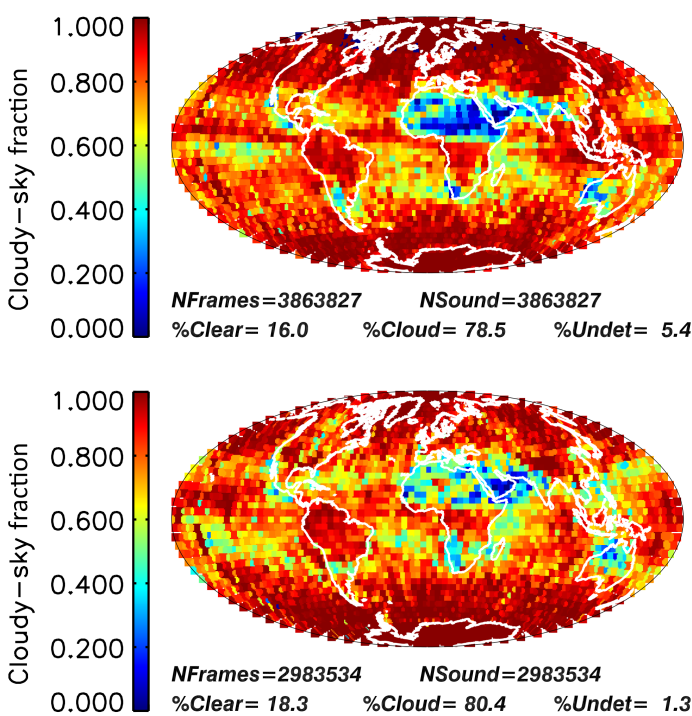

Figure 4. Cloudy-sky fraction calculated from the MODIS/OCO2 collocated cloud mask described in Sect. 3.2 for the December combined glint and nadir data sets (top) and the April-May data (bottom). Data are binned in $4^{\circ}$ by $4^{\circ}$ lat/long boxes.

oceans have cloud fractions ranging from about 50 to $100 \%$. The global mean fraction of cloudy scenes is around $80 \%$, in close agreement with that reported in Fig. 13 of Miller et al. (2007).

\subsection{CALIOP layered data}

The CALIOP collocated product used in this work is comprised of 233 orbits, spanning days 7 to 22 May 2015. For each OCO-2 sounding, the CALIOP data point with the closest latitude and longitude to the OCO-2 footprint was selected. In this analysis, we limited the data to soundings falling within $5 \mathrm{~km}$ to minimize the differences in the observed atmospheric and surface conditions. This provided a mean FOV difference of $3.0 \mathrm{~km}$ (and about $7 \mathrm{~min}$ due to difference in overpass times) for the collection. Two useful cloud metrics, derived from these CALIOP data, were used to analyze the performance of the OCO-2 cloud screening algorithms.

The sum of the cloud and aerosol optical depths at $532 \mathrm{~nm}$, taken from the $5 \mathrm{~km}$ cloud and aerosol layered products, respectively, provided the reference total optical depth $\left(\mathrm{TOD}_{532 \mathrm{~nm}}\right.$ ) corresponding to each collocated OCO-2 sounding. The effective cloud top pressure $\left(p_{\mathrm{c}}\right)$ for each CALIOP collocation was calculated by integrating TOD $_{532 \mathrm{~nm}}$ vertically through the atmosphere (starting at the top) until TOD $_{532 \mathrm{~nm}}>1$ was achieved. The pressure value at the center of that layer was then assumed to represent $p_{\mathrm{c}}$. This value was then normalized by the ECMWF model surface pressure (taken from the ABP prior) to give the normalized effective cloud top pressure, $\bar{p}_{\mathrm{c}}$. Thus, lowaltitude clouds correspond to $\bar{p}_{\mathrm{c}}$ values near unity, while clouds higher in the atmosphere are represented by $\bar{p}_{\mathrm{c}}$ values near 0 . This quantity is similar to, but slightly different from, the cloud relative height that was described for the simulations in Sect. 2.3.

Expressions for determining $\bar{p}_{\mathrm{c}}$ are given as

$\operatorname{TOD}\left(p_{\mathrm{c}}\right)=1=\sum_{p(\mathrm{TOA})}^{p_{\mathrm{c}}} \operatorname{TOD} \Delta p, \quad \bar{p}_{\mathrm{c}}=p_{\mathrm{c}} / p_{\mathrm{s}}$,

where $p_{\mathrm{s}}$ gives the surface pressure.

There is a spectral mismatch when comparing the CALIOP measurements at $532 \mathrm{~nm}$, to the OCO- 2 cloud screening results, which use measurements taken at 760 , 1610 and $2060 \mathrm{~nm}$. It is possible that this could lead to disagreements in classifying contaminated soundings, especially for scenes containing small aerosol particles, i.e., large Ångström coefficients, a condition in which the measurements from the two sensors need to be made at the same spectral points. Some errors will exist in the agreement between the two sensors reported in the current study due to this spectral mismatch, as well as the small spatial and temporal discrepancies described above.

\section{Validation of OCO-2 cloud screening algorithms}

\subsection{Contingency table analysis}

In this section, we directly compare the OCO-2 and MODIS cloud screening results. This is done via contingency tables (CT), which provide compact summary statistics for comparing large predictive data sets. This analysis follows that given in Taylor et al. (2012) on GOSAT data. For each sounding, there are four classification possibilities. The cloud screening algorithms can agree that the scene is clear or cloudy: true positives (TP) and true negatives (TN), respectively. Soundings can also be classified as false positives (FP), when MODIS indicates cloud but OCO-2 identifies the scene as clear, or false negatives (FN), when MODIS indicates clear but OCO- 2 cloud. The classification of scenes by MODIS will be referred to as the "reference" state, while scene classification by the OCO-2 preprocessors will be termed the "predicted" state.

Each CT value can be interpreted in terms of a rate, calculated as

$$
\begin{array}{ll}
\text { true positive rate (TPR) } & =N_{\mathrm{TP}} / N_{\text {clear }}, \\
\text { false negative rate (FNR) } & =N_{\mathrm{FN}} / N_{\text {clear }}, \\
\text { false positive rate (FPR) } & =N_{\mathrm{FP}} / N_{\text {cloud }}, \\
\text { true negative rate (TNR) } & =N_{\mathrm{TN}} / N_{\text {cloud }},
\end{array}
$$

where $N_{\mathrm{TP}}, N_{\mathrm{FN}}, N_{\mathrm{FP}}$ and $N_{\mathrm{TN}}$ are the number of collocated TP, FN, FP and TN soundings, respectively, and $N_{\text {clear }}$ and $N_{\text {cloud }}$ give the number of reference clear and cloudy atmospheres, respectively. 

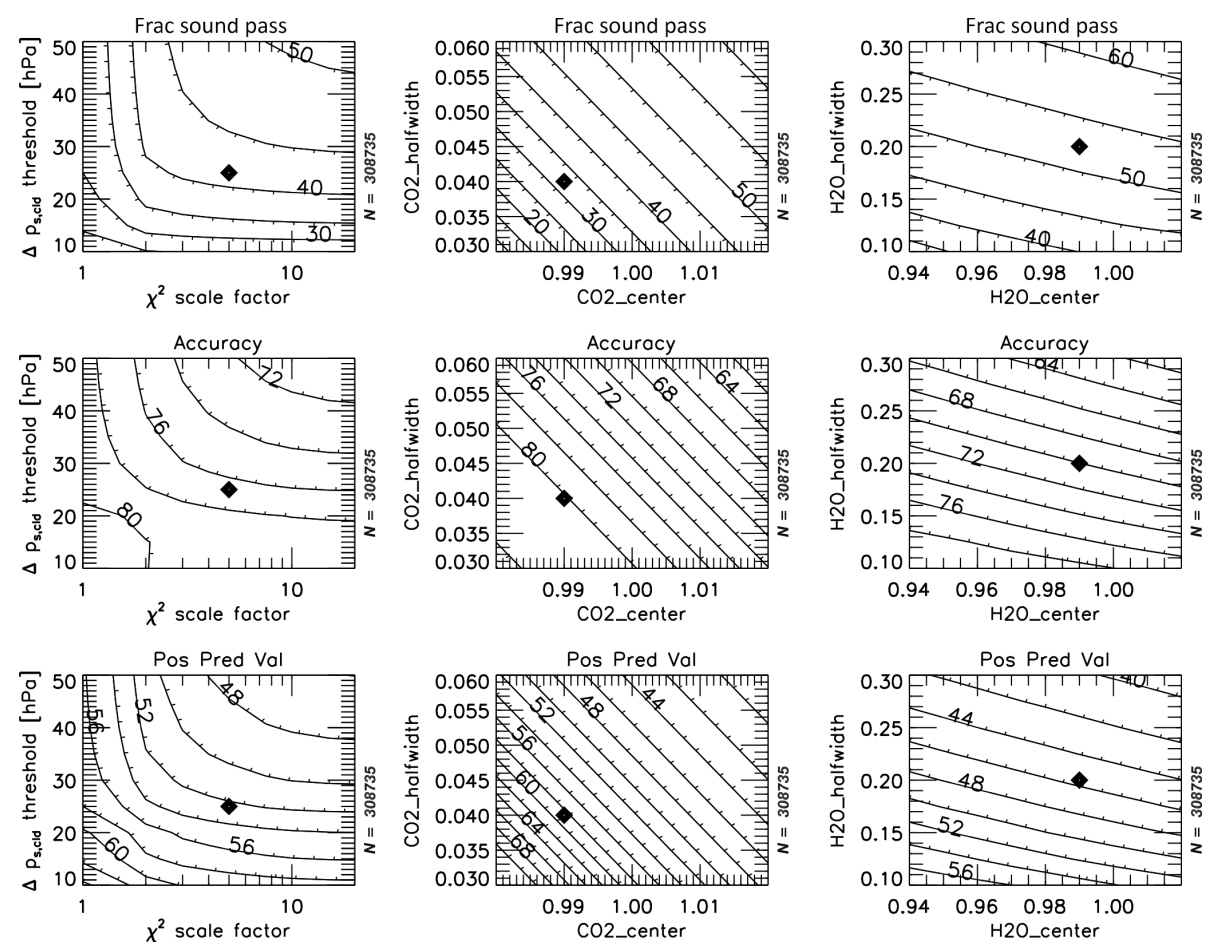

Figure 5. Contour plots of the May nadir-land data showing the fraction of soundings passing (top row), agreement (middle row) and positive

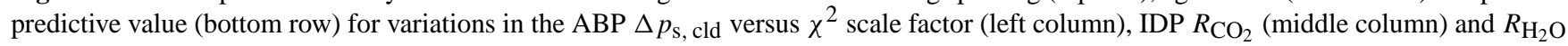
(right column). Contours are drawn at increments of $5 \%$ for the fraction passing and $2 \%$ for the agreement and positive predictive values. The black diamond represents the threshold settings adopted for the analysis presented in this work.

Three useful diagnostic variables can be calculated from the $\mathrm{CT}$ values:

$$
\begin{aligned}
& \text { throughput }=\left(N_{\mathrm{TP}}+N_{\mathrm{FP}}\right) / N_{\text {total }}, \\
& \text { agreement }=\left(N_{\mathrm{TP}}+N_{\mathrm{TN}}\right) / N_{\text {total }}, \\
& \text { positive predictive value }(\mathrm{PPV})=N_{\mathrm{TP}} /\left(N_{\mathrm{TP}}+N_{\mathrm{FP}}\right),
\end{aligned}
$$

where $N_{\text {total }}=N_{\text {clear }}+N_{\text {cloud }}=N_{\mathrm{TP}}+N_{\mathrm{FN}}+N_{\mathrm{FP}}+N_{\mathrm{TN}}$ is the total number of collocated scenes.

The throughput gives the fraction of the total number of collocated scenes that are identified as clear by the OCO-2 cloud screening algorithms. The agreement gives the fraction of scenes that are correctly predicted by the OCO-2 cloud screening algorithms, relative to the MODIS reference state. The positive predictive value (PPV) gives the fraction of the reference clear soundings, i.e., the MODIS clear soundings, also predicted clear by the OCO-2 preprocessors.

\subsection{Optimization of the cloud screening algorithm thresholds for the MODIS comparison}

We now use CT analysis to explore the optimization of the OCO-2 ABP and IDP cloud screening algorithms by calculating an ensemble of CT diagnostics given in Eq. (4) for varying values of the cloud screening thresholds. This analysis was performed using the OCO-2 data sets that were introduced in Sect. 3.
Systematic variations in the threshold values are expected to alter the diagnostic values. The objective is to develop filters such that a tightening (i.e., narrowing) of the thresholds generally yields an increase in the agreement and the PPV, while simultaneously decreasing the throughput. Given filters that satisfy these rules, an aggressive cloud screening can be achieved by tightening the thresholds. Conversely, if the design goal is to filter only the most grossly contaminated scenes while maximizing the throughput at the expense of the agreement, then the filtering thresholds can be set to relatively loose values. For OCO-2, our design goal is to pass approximately $25-30 \%$ of soundings without introducing spatial sampling biases. This value corresponds to 5-10\% more than the clear-sky fraction observed by MODIS. This inflation over the MODIS number is necessary since some of the passed soundings are actually cloudy. It is crucial that as many of the scenes as possible are correctly classified, while limiting the number of false negative cases (MODIS clear, OCO-2 cloudy), as once a sounding has been identified as cloudy by either $\mathrm{ABP}$ or IDP, it will not to be run in the operational $\mathrm{L} 2 \mathrm{X}_{\mathrm{CO}_{2}}$ retrieval algorithm.

The left column of Fig. 5 shows contour plots of the throughput, agreement and PPV for the May nadir-land OCO-2 soundings as a function of the $\Delta p_{\mathrm{s} \text {, cld }}$ and the $\chi^{2}$ scaling factor, the two primary screening thresholds for the ABP algorithm. The tradeoff in trying to maximize all three 
Table 3. Contingency tables for the comparison of the OCO-2 cloud screening preprocessors to MODIS cloud mask. Results are shown for the three main viewing scenarios for both the winter (December) and spring (April-May) data sets.

\begin{tabular}{|c|c|c|c|c|c|c|c|c|c|c|c|c|c|}
\hline \multirow[t]{3}{*}{ Viewing } & \multicolumn{3}{|c|}{ Reference clear atmospheres } & \multicolumn{7}{|c|}{ Reference cloudy atmospheres } & \multirow[t]{3}{*}{ Throughput } & \multirow[t]{3}{*}{ Agreement } & \multirow[t]{3}{*}{ PPV } \\
\hline & \multirow[t]{2}{*}{$\begin{array}{l}\text { Total } \\
\text { cases }\end{array}$} & \multicolumn{2}{|l|}{$\begin{array}{l}\text { Predicted } \\
\text { clear }\end{array}$} & \multicolumn{2}{|c|}{$\begin{array}{l}\text { Predicted } \\
\text { cloudy }\end{array}$} & \multirow[t]{2}{*}{$\begin{array}{l}\text { Total } \\
\text { cases }\end{array}$} & \multicolumn{2}{|c|}{$\begin{array}{l}\text { Predicted } \\
\text { clear }\end{array}$} & \multicolumn{2}{|l|}{$\begin{array}{l}\text { Predicted } \\
\text { cloudy }\end{array}$} & & & \\
\hline & & $N_{\mathrm{TP}}$ & TPR & $N_{\mathrm{FN}}$ & FNR & & $N_{\mathrm{FP}}$ & FPR & $N_{\mathrm{TN}}$ & TNR & & & \\
\hline \multicolumn{14}{|c|}{ Winter (December) } \\
\hline Nadir-land & 97321 & 73633 & $75.7 \%$ & 23688 & $24.3 \%$ & 559799 & 95049 & $17.0 \%$ & 464750 & $83.0 \%$ & $25.7 \%$ & $81.9 \%$ & $43.7 \%$ \\
\hline Glint-land & 69877 & 48698 & $69.7 \%$ & 21179 & $30.3 \%$ & 309357 & 24931 & $8.1 \%$ & 284426 & $91.9 \%$ & $19.4 \%$ & $87.8 \%$ & $66.1 \%$ \\
\hline Glint-water & 143295 & 110275 & $77.0 \%$ & 33020 & $23.0 \%$ & 687447 & 72694 & $10.6 \%$ & 614753 & $89.4 \%$ & $22.0 \%$ & $87.3 \%$ & $60.3 \%$ \\
\hline \multicolumn{14}{|c|}{ Spring (April-May) } \\
\hline Nadir-land & 78929 & 52772 & $66.9 \%$ & 26157 & $33.1 \%$ & 229057 & 27992 & $12.2 \%$ & 201065 & $87.8 \%$ & $26.2 \%$ & $82.4 \%$ & $65.3 \%$ \\
\hline Glint-land & 88401 & 49660 & $56.2 \%$ & 38741 & $43.8 \%$ & 358799 & 34248 & $9.5 \%$ & 324551 & $90.5 \%$ & $18.8 \%$ & $83.7 \%$ & $59.2 \%$ \\
\hline Glint-water & 205204 & 143568 & $70.0 \%$ & 61636 & $30.0 \%$ & 959801 & 81897 & $8.5 \%$ & 877904 & $91.5 \%$ & $19.4 \%$ & $87.7 \%$ & $63.7 \%$ \\
\hline
\end{tabular}

diagnostic parameters simultaneously is evident. In general, as the agreement and PPV increase with tighter choices of $\Delta p_{\mathrm{s} \text {, cld }}$ and $\chi^{2}$ scale factor, the throughput decreases. For this particular data set, setting $\Delta p_{\mathrm{s}, \text { cld }}$ to $25 \mathrm{hPa}$ and $\chi^{2}$ scale factor to 5 allows a throughput $\simeq 42 \%$, with agreement $\simeq 77 \%$ and $\mathrm{PPV} \simeq 52 \%$. The operational settings of the OCO-2 ABP since the on-orbit instrument checkout phase (September 2014) have been $25 \mathrm{hPa}$ and $\chi^{2}$ scale factor $=20$. Studies showed that for nadir-land and glint-ocean viewing the $\Delta p_{\mathrm{s} \text {, cld }}$ filter alone flags approximately $98 \%$ of the soundings determined cloudy by ABP, while the surface albedo check provides significant filtering (up to $25 \%$ of cloudy scenes) for glint-land viewing.

The inclusive ranges of the IDP $R_{\mathrm{CO}_{2}}$ and $R_{\mathrm{H}_{2} \mathrm{O}}$ values are described by a center point plus and minus a half-width value. The middle and right columns of Fig. 5 show results from the optimization testing for IDP $R_{\mathrm{CO}_{2}}$ and $R_{\mathrm{H}_{2} \mathrm{O}}$ half-width versus center point values, respectively. Values of $0.99 \pm 0.04$ and $0.99 \pm 0.2$ for nadir-land were selected for $R_{\mathrm{CO}_{2}}$ and $R_{\mathrm{H}_{2} \mathrm{O}}$, respectively, as shown in Table 1 . These values were then implemented in the cloud screen comparison to MODIS that will be detailed in Sect. 4.3. Note that the results for the glint-land and glint-water viewing scenarios differed slightly compared to the nadir-land results, as shown in Table 1. Furthermore, slight differences were observed between the winter and spring data sets, indicating that the thresholds values should be carefully selected to minimize over-filtering of the data.

\subsection{Validation of OCO-2 cloud screening algorithms against MODIS}

After optimization of the cloud screening thresholds, contingency tables were generated using the combined ABP and IDP algorithms. The analysis was performed separately for each of the three viewing scenarios: nadir-land, glint-land and glint-water using the data sets for the four 16-day repeat cycles referenced in Table 2. The results of the CT analysis are displayed in Table 3.
Overall, the results are very encouraging. The throughputs using the combined $\mathrm{ABP}$ and IDP cloud screenings range from $20 \%$ for the spring glint-water data to $31 \%$ for the spring glint-land data. Agreement with MODIS for the six data sets ranges from a low of $79 \%$ for spring glint-land to $88 \%$ for spring glint-water. Finally, the positive predictive values range from $46 \%$ for winter land (both nadir and glint) to $67 \%$ for spring nadir-land.

The roughly $15-20 \%$ of scenes that are in disagreement can be explained by a number of factors, one being the stringent MODIS search criteria for defining the reference scene as clear or cloudy. In some cases, one or two of the approximately 10 MODIS pixels that are matched to a single OCO-2 footprint may be labeled as probably or confidently cloudy. This causes the reference scene to be defined as cloudy, although the OCO-2 footprint itself may be observing clearsky. In addition, an OCO-2 footprint can potentially miss sub-FOV clouds as demonstrated by Merrelli et al. (2015). These very same scenes would presumably have been identified as cloudy by MODIS, which has a smaller spatial footprint. Finally, the OCO-2 "cloud mask" does not discriminate aerosol versus cloud. Therefore, some aerosol-laden clear scenes will be correctly identified by MODIS as clear, and correctly identified by OCO-2 as cloudy, because of this difference in definition.

Another fundamental reason for disagreement between the OCO-2 cloud screening algorithms and MODIS is that the comparisons are in reference to MODIS as truth, an assumption that is not void of uncertainties. There are errors inherent in comparing cloud screening between satellite sensors with very different instrument characteristics and specifications which are not viewing exactly the same scene with the same viewing geometry at the same time. Furthermore, the cloud screen threshold values were selected to be relatively loose. As was discussed in Sect. 4.2, tighter thresholds generally increase PPV but reduce the throughput.

The contingency table analysis given in Table 3 indicates the good agreement for the reference cloudy scenes 

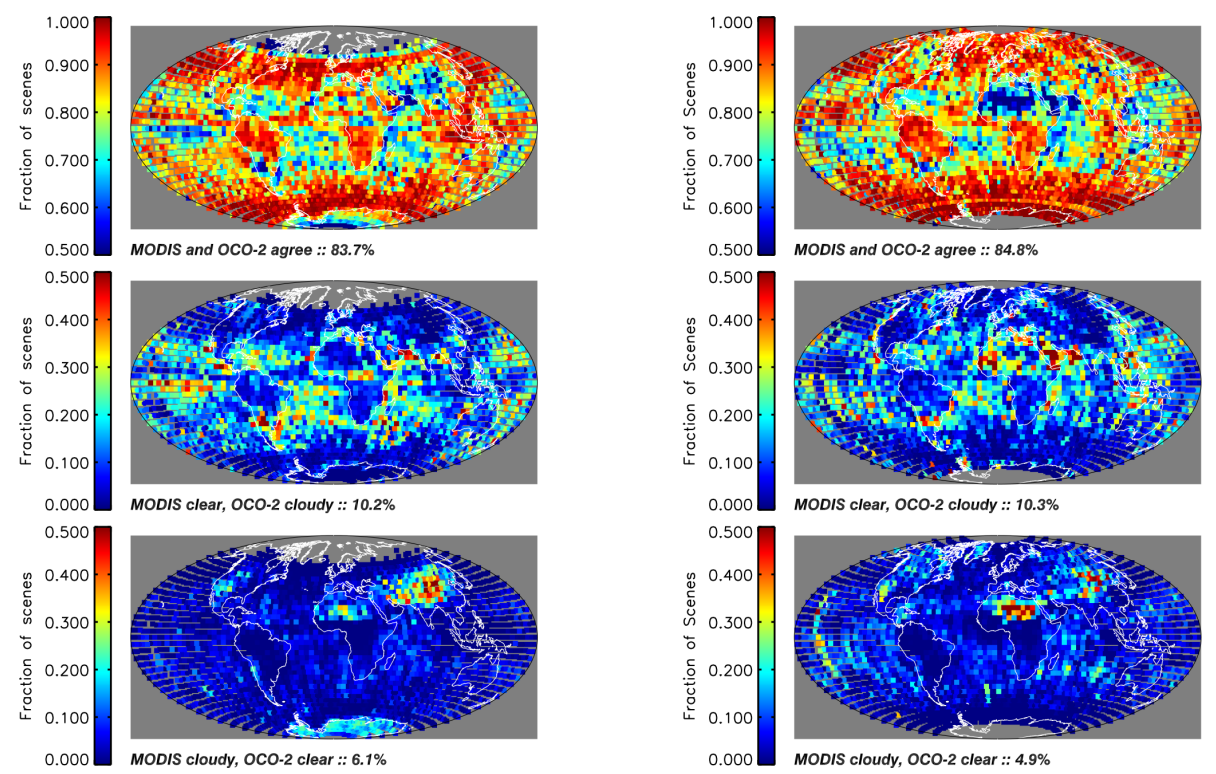

Figure 6. Combined glint and nadir gridded contingency table data for December (left column) and April-May (right column). Data are binned on a $4^{\circ}$ by $4^{\circ}$ lat/long grid. Scenes for which MODIS and OCO-2 cloud screenings agree are shown in the top panel, while the two types of disagreement - MODIS clear, OCO-2 cloudy and vice versa - are shown in the two lower rows, respectively. The color scales span the range $50-100 \%$ for the "agree" panels and 0-50\% for the "disagree" panels.

(TNR $\simeq 80-90 \%)$ versus the lower agreement for the reference clear scenes $(\mathrm{TPR} \simeq 65-75 \%)$. This indicates that the OCO-2 cloud screening algorithms, as configured in this study, are more aggressive, i.e., use more stringent filtering thresholds than MODIS does. This makes sense, as OCO-2 is sensitive to both clouds and aerosols, while the MODIS cloud mask product identifies only water and ice clouds.

An investigation of the eight OCO-2 footprints per frame via CT statistics reveals no strong footprint dependence. The range of variability for all of the $\mathrm{CT}$ values across footprints is always well under $2 \%$ and is generally closer to $1 \%$, which is essentially within the noise.

It is critical to avoid latitudinal sampling biases in the measurement of $\mathrm{X}_{\mathrm{CO}_{2}}$, as these can yield serious errors in flux inversion estimates (Liu et al., 2014). To assess the spatial distributions of the contingency table values in the current analysis, the combined glint and nadir data sets were gridded into $4^{\circ}$ latitude by $4^{\circ}$ longitude bins, and the fractions that agree and disagree in each bin were calculated. The results are presented in Fig. 6, which shows the winter data in the left column and the spring data on the right. The top panels show that the global agreement of $\simeq 85 \%$ in both seasons (and for all viewing geometries) contains large, spatially correlated regions with $>90 \%$ agreement over much of the total land mass as well as the northern Atlantic, northern Pacific, eastern Indian and Southern oceans. Other regions generally have cloud screening agreement $\simeq 70-80 \%$, with a few areas agreeing less than $60 \%$ of the time, such as certain ocean regions and northern Africa in April-May.
The middle and bottom panels of Fig. 6 show the two types of disagreement in the cloud screeners: false negatives (MODIS clear, OCO-2 cloudy) and false positives (MODIS cloudy, OCO-2 clear), respectively. The false negative errors tend to occur over tropical and subtropical oceans. The reason for this disagreement is unclear, but it seems to imply that these are very thin cloud cases to which OCO-2 is more sensitive than MODIS. The false positive errors, shown in the lower panels, are heavily concentrated over the Sahara and Tibetan plateau land regions, where some grid cells exceed $50 \%$ of scenes in disagreement in spring. These are very likely to be driven by desert dust and topographic features, as discussed below.

Differences in the spatial patterns are evident when comparing the winter and spring data, although the global statistical agreements are very similar $(86 \%$ for winter versus $85 \%$ for spring). There are three obvious difference features over land, each of which may be manifestations of distinct issues. One major difference in the seasonal cloud screening agreement is seen over the Arabian peninsula, where the fraction of false negatives increased from near $0 \%$ in winter to $40-50 \%$ or more in spring. These misclassifications appear to be driven by a high aerosol loading. Specifically, the MODIS cloud mask correctly identifies these scenes as clear, but a single case study of the MODIS Deep Blue derived AODs (Hsu et al., 2013) revealed that sometimes these scenes are heavily aerosol laden. Implementation of the MODIS Deep Blue AODs into the definition of cloudy/clear used in this work may provide slightly improved agreement between OCO-2 and MODIS cloud screening. However, the 
collocated product was not available at the time this research was performed. As stated above, the OCO-2 screening algorithms do not discriminate between aerosol and cloud, and hence they identify any scenes that are contaminated by cloud and/or aerosol.

The second significant temporal difference feature over land is seen over the Sahara, where the fraction of false positive scenes (MODIS cloudy, OCO-2 clear) increases from about $25 \%$ to more than $50 \%$ from winter to spring. Observations from the Total Ozone Mapping Spectrometer (TOMS) indicate increased dust loads over this region during the warmer months (peak in June and July), with a minimum in October and November (Engelstaedter et al., 2006). The reason for the disagreement here is unclear, though it seems unlikely that MODIS would be incorrectly identifying dust-laden scenes as cloudy, while OCO-2 identifies them as clear. These cases warrant further investigation to identify the source of this discrepancy.

Finally, the distribution of the false positive scenes over the Tibetan plateau decreases in spatial extent from winter to spring but becomes more concentrated in the eastern edge. This phenomena may be driven by the extreme topography and/or snow cover of this region, though at this point it is not clear which of the two cloud screeners (MODIS or OCO-2) is in error.

The spatial change in the agree/disagree distribution from winter to spring is less pronounced over ocean compared to land. The most distinct signal is a tracking of the sub-solar point as it moves northward between the seasons. This would indicate a largely SNR-driven issue, i.e., as the SNR of OCO2 increases, so too does the sensitivity to very mild scattering effects. Most of the disagreements over ocean are of the false negative type (MODIS clear, OCO-2 cloudy), which, as stated previously, could be due to a more sensitive cloud identification by OCO-2 relative to MODIS.

In general, the global patterns in the cloud screening agreements between winter and spring look much the same, indicating that there does not appear to be strong seasonally dependent sampling biases in the OCO- 2 cloud screened data set. The spatial and temporal differences have, for the most part, been explained, although a rigorous analysis and verification of the proposed hypotheses has yet to be made.

\subsection{Validation of OCO-2 cloud screening algorithms against CALIPSO}

The next step in our validation of the OCO-2 cloud screening algorithms was to assess the cloud screening performance against collocated CALIOP measurements. The CALIOP $\mathrm{TOD}_{532 \mathrm{~nm}}$ and the normalized effective cloud top pressure $\left(\bar{p}_{\mathrm{c}}\right)$, introduced in Sect. 3.3, were used. CALIOP is more sensitive to low optical thicknesses than MODIS, and it provides information on the vertical structure of scattering layers, allowing for a more quantitative analysis of the OCO-2 cloud screening abilities and a basis for investigating sound-
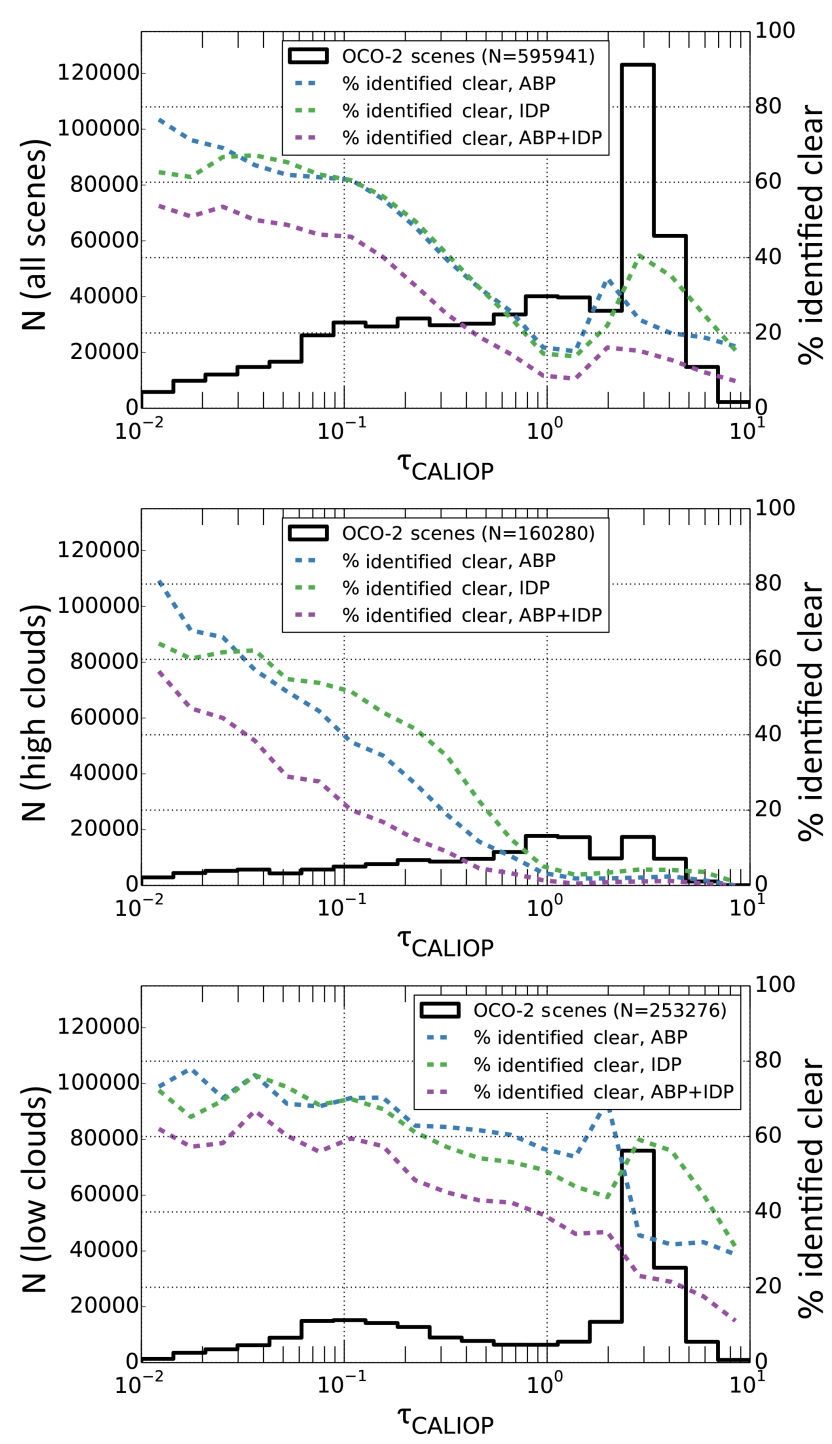

Figure 7. Comparison of OCO-2 cloud screening to CALIOP optical depth measurements for collocated soundings. Histograms of the number of OCO-2 soundings are shown as black solid trace against the left ordinate, and percent of soundings identified as clear versus the CALIPSO optical depth are shown against the right ordinate. Only the May nadir-land viewing data were used. Each panel shows results for the combined ABP + IDP (pink), the ABP only (blue) and IDP only (green). The top panel uses the total number of scenes, while the middle and lower panel use only the high-cloud and low-cloud scenes, respectively, where high and low clouds are defined in the text.

ings for which the OCO-2 and MODIS cloud screenings differ.

Figure 7 demonstrates the performance of the OCO-2 cloud screening relative to CALIOP data for the May nadirland observations. The analysis is restricted to nadir observations because the small swath of CALIOP does not allow for collocation with OCO-2 in glint viewing mode. The top 
panel shows the percent of soundings identified as clear (right ordinate) against the CALIOP TOD $532 \mathrm{~nm}$ for the ABP-only (blue), the IDP-only (green) and combined ABP and IDP (pink). The cloud screening thresholds were set to similar, but not identical, values as those reported in Sect. 4.2 in order to provide a throughput of $\simeq 30 \%$. The histogram of the number of soundings at each TOD $532 \mathrm{~nm}$ is shown against the left ordinate. The distribution of CALIOP TOD $532 \mathrm{~nm}$ ranges from 0.01 to 10 , at which point the instrument saturates. For this particular data set, approximately half of the total number of scenes have TOD $_{532 \mathrm{~nm}}>1$. Note that scenes with CALIOP TOD $532 \mathrm{~nm}=0$ were not used in this analysis.

The three panels show the results for all scenes (top), high clouds only (middle) and low clouds only (bottom), where high (low) is defined as cases where $95 \%$ of the CALIOP $\mathrm{TOD}_{532 \mathrm{~nm}}$ resides in the top $40 \%$ (bottom $30 \%$ ) of the atmosphere. Approximately $25 \%$ of the scenes are classified as high cloud while approximately $40 \%$ are classified as low cloud.

For each of the cloud distribution data sets (total, high and low) the fraction of scenes identified as clear is anticorrelated with the CALIOP TOD $_{532 \mathrm{~nm}}$ for all three cloud screening combinations, as expected. That is, as the TOD increases, the fraction of scenes identified as clear decreases.

For the all-clouds case (top panel), the ABP and IDP give very similar performance when CALIOP $\mathrm{TOD}_{532 \mathrm{~nm}}<1$, while for $\mathrm{TOD}_{532 \mathrm{~nm}}>1$ the ABP and IDP each have a spike in the clear-sky rate. One hypothesis is that there is a sweet spot where the clouds are just thick enough to cause multiple scattering effects, which result in a path length indistinguishable from perfectly clear scenes. That is, the preprocessors think they are seeing the surface and thus mistakenly identify the scene as clear. The combined effect of the two filters is to screen out more than $80 \%$ of the optically thick scenes.

We would expect that at very low true optical depths $(\mathrm{OD}<0.1)$ nearly all scenes would be identified by OCO-2 as clear and conversely that OCO-2 would identify as cloudy nearly all optically thick scenes $(\mathrm{OD}>1)$. This was indeed the case for simulations, as shown previously in Fig. 2. However, OCO-2 labels as cloudy about $50 \%$ of the scenes with CALIOP $0.0<$ TOD $_{532 \mathrm{~nm}}<0.1$. This could be due in part to imperfect collocation between OCO-2 and CALIOP, as the distance between observations of the two sensors can be as large as $5 \mathrm{~km}$ and a temporal discrepancy of about $7 \mathrm{~min}$ exists between the local overpass times of the two satellites. In addition, the smaller CALIOP ground footprint $\left(\simeq 0.02 \mathrm{~km}^{2}\right)$ compared to OCO-2 ( $\simeq 0.2$ to $3 \mathrm{~km}^{2}$, depending on latitude) means that CALIOP is more likely to observe scenes free of cloud in broken cloud fields. Furthermore, the OCO-2 cloud screening thresholds have been set to pass $\simeq 30 \%$ of soundings, which means some optically thin scenes will pass.

To access the performance of the cloud screening algorithms as a function of cloud height, the same analysis was conducted separately on the high-cloud and low-cloud populations as demonstrated in the lower panels of Fig. 7. It

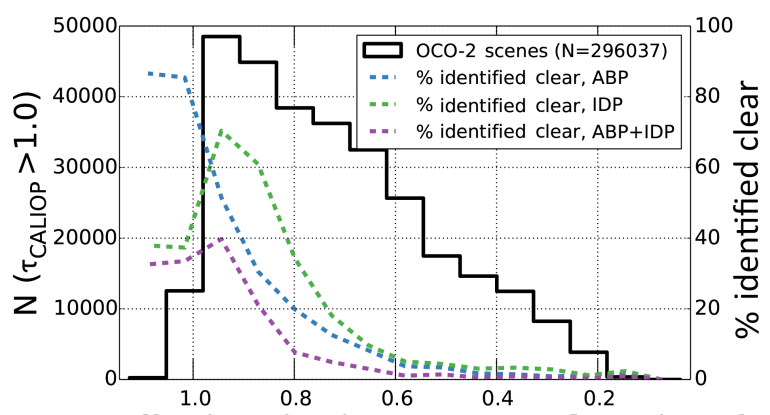

CALIOP effective cloud top pressure [ fraction of $\mathrm{P}_{\mathrm{sfc}}$ ]

Figure 8. Histogram of the number of OCO-2 soundings with CALIOP optical depth $>1$ (solid trace against the left ordinate) and percent of soundings (dotted traces against the right ordinate) identified as clear versus the CALIOP effective cloud top pressure (defined in the text) for the May nadir-land viewing data. The results for the combined ABP + IDP are shown in pink, the ABP only in blue and IDP only in green.

is evident that both ABP and IDP cloud screeners pass as clear only a small fraction $(<5 \%)$ of the high clouds with $\mathrm{TOD}_{532 \mathrm{~nm}}>1$. However, it fails to identify many of the scenes with thick, low clouds. Exactly the same behavior was identified for ABP in the simulation-based studies described in Sect. 2.3 and shown in Fig. 2.

To further assess scenes with relatively high optical thicknesses that are erroneously passing the OCO-2 cloud screening algorithms, a subset of the data was created to include only those soundings with CALIOP TOD $532 \mathrm{~nm}>1$. The performance of the OCO-2 cloud screening algorithms on this subset of soundings was analyzed against the effective cloud top pressures to demonstrate the behavior as a function of scattering height. The results from this analysis are shown in Fig. 8, which shows the frequency distribution and the fraction of scenes identified as clear as a function of the CALIOP normalized cloud top pressure $\left(\bar{p}_{\mathrm{c}}\right.$, defined by Eq. (2) in Sect. 3.3). The pink trace shows results for the combined $\mathrm{ABP}$ and IDP filters while the blue and green traces shows results utilizing only the ABP and only the IDP, respectively.

At $\bar{p}_{\mathrm{c}} \simeq 0.95$ (low-altitude clouds), about $60 \%$ of the scenes are identified as clear by both the ABP and IDP, while combining the two reduces the pass rate to about $40 \%$ for these low, optically thick scenes. In contrast, when $\bar{p}_{\mathrm{c}}<0.4$ (high-altitude clouds), the pass rate of the combined cloud screening algorithms is less than $1 \%$.

These results suggest that the ABP, which relies on PPL modification to detect cloud, is unable to discern cloud near the surface, even when the optical thickness is large. Conversely, $\mathrm{ABP}$ is sensitive to very thin scattering layers when they are located high in the atmosphere due to the strong PPL modification. Again, both of these behaviors were first identified in simulations as seen in Fig. 2 and have now been demonstrated with real data. 


\section{Conclusions}

In this work, we have shown that the OCO-2 cloud screening preprocessors perform well in comparison to the MODISAqua cloud mask on a large, global data set consisting of four 16-day orbit track repeat cycles in both nadir and glint viewing modes. Overall, the OCO-2 cloud screening algorithms meet the need for prescreening the data before further processing in the $\mathrm{L} 2 \mathrm{X}_{\mathrm{CO}_{2}}$ retrieval algorithm. We have demonstrated that the ABP and IDP algorithms can be sufficiently tuned to pass $\simeq 20-25 \%$ of the data while maintaining overall agreement of $\simeq 85 \%$ with the MODIS cloud mask.

The primary objective of the ABP and IDP cloud screening algorithms is to accurately identify and discard contaminated soundings that are unlikely to yield accurate estimates of $\mathrm{X}_{\mathrm{CO}_{2}}$. However, it is also important that these screens are not so aggressive that they eliminate clear soundings in partially cloudy regions, because this could introduce sampling biases in $\mathrm{CO}_{2}$ source/sink inversion models. We find that the OCO-2 cloud screening algorithms are passing soundings over all portions of the globe, although higher latitudes and higher solar zenith angles tend to be problematic due to snow- and ice-covered surfaces and lower signal-to-noise ratios, respectively, both of which make reliable cloud identification and $\mathrm{X}_{\mathrm{CO}_{2}}$ retrievals difficult.

We find that approximately $10 \%$ of soundings are identified as clear by MODIS and cloudy by OCO-2, while approximately $5 \%$ are identified as cloudy by MODIS and clear by OCO-2. The former disagreement type is likely due to the enhanced sensitivity of OCO-2 to atmospheric scattering as compared to MODIS, or due to the presence of aerosol (which OCO-2 sees but the MODIS cloud mask does not), while the latter condition is partially attributed to the moderately loose OCO-2 cloud screening thresholds applied in this work. Some of both types of disagreements are likely to be caused by minor spectral, spatial and temporal mismatches in comparing different satellite sensors.

Simulations of OCO-2 observations suggest that the ABP reliably identifies optically thin high clouds. This conclusion is confirmed by comparisons with collocated CALIOP data. In addition, we confirmed the ABP's limitation for identifying low-altitude clouds, even those with total optical depths well above what can be analyzed to yield accurate $\mathrm{X}_{\mathrm{CO}_{2}}$ retrievals. However, the combination of the ABP with the IDP reduces the number of the low, thick clouds that are being erroneously identified as clear.

Detailed studies uncovered no significant time-dependent or footprint-dependent features in the OCO-2 cloud screening algorithms. Although the operational sounding selection plan for OCO-2 is constantly evolving, it will continue to rely in part on the cloud screening results provided by the ABP and IDP, which have been shown here to be in reasonably good agreement with both MODIS and CALIOP. Finally, we note that though OCO-2 was designed primarily to measure atmospheric $\mathrm{CO}_{2}$, it is evident that the instrument is very sen- sitive to scattering in the atmosphere by clouds and aerosols, and thus future cloud and/or aerosol studies may benefit from an examination of how OCO-2's unique capabilities can contribute.

Acknowledgements. The CSU contribution to this work was supported by JPL subcontract 1439002. A portion of the research described in this paper was carried out at the Jet Propulsion Laboratory, California Institute of Technology, under a contract with the National Aeronautics and Space Administration.

We would like to acknowledge the hard work of those individuals on the OCO-2 algorithm and data processing teams whose efforts helped make this work possible. The list (in alphabetical order) includes (but is not limited to) Charlie Avis, Lars Chapsky, Lan Dang, Robert Granat, Richard Lee, Lukas Mandrake, James McDuffie, Vijay Natraj, Fabian Oyafuso, Vivienne Payne, Rob Rosenberg, Mike Smyth, Paul Wennberg, Debra Wunch and Jia Zong, all at JPL.

We would also like to acknowledge the contributions made by the GOSAT JAXA and NIES teams that made this research possible.

In addition we thank the computer support staff at CSU, Natalie Tourville and Michael Hiatt.

Finally, we thank the two anonymous reviewers and the journal editor and staff who provided useful comments and helped typeset the manuscript.

Edited by: A. Kokhanovsky

\section{References}

Ackerman, S. A., Strabala, K. I., Menzel, W. P., Frey, R. A., Moeller, C. C., and Gumley, L. E.: Discriminating clear sky from clouds with MODIS, J. Geophys. Res., 103, D07206, doi:10.1029/1998JD200032, 1998.

Ackerman, S. A., Holz, R., Frey, R., Eloranta, E., Maddux, B., and McGill, M.: Cloud detection with MODIS Part II: Validation, J. Atmos. Ocean Tech., 25, 1073-1086, doi:10.1175/2007JTECHA1053.1, 2008.

Bösch, H., Toon, G. C., Sen, B., Washenfelder, R. A., Wennberg, P. O., Buchwitz, M., de Beek, R., Burrows, J. P., Crisp, D., Christi, M., Connor, B. J., Natraj, V., and Yung, Y. L.: Spacebased near-infrared $\mathrm{CO}_{2}$ measurements: Testing the Orbiting Carbon Observatory retrieval algorithm and validation concept using SCIAMACHY observations over Park Falls, Wisconsin, J. Geophys. Res., 111, D23302, doi:10.1029/2006JD007080, 2006.

Bösch, H., Baker, D., Crisp, D., and Miller, C.: Global characterization of $\mathrm{CO}_{2}$ column retrievals from shortwave-infrared satellite observations of the Orbiting Carbon Observatory-2 mission, Remote Sens., 3, 270-304, doi:10.3390/rs3020270, 2011.

Bösch, H., Brown, L., Castano, R., Christi, M., Connor, B., Crisp, D., Eldering, A., Fisher, B., Frankenberg, C., Gunson, M., Granat, R., McDuffie, J., Miller, C., Natraj, V., O’Brien, D., O’Dell, C., Osterman, G., Oyafuso, F., Payne, V., Polonsky, I., Smyth, M., Spurr, R., Thompson, D., and Toon, G.: Orbiting Carbon Observatory (OCO)-2 Level 2 Full Physics Retrieval Algorithm Theoretical Basis Document, available at: http://disc.sci.gsfc.nasa.gov/OCO-2/documentation/oco-2-v6/ OCO2_L2_ATBD.V6.pdf, (last access: 1 March 2016), 2015. 
Butz, A., Guerlet, S., Hasekamp, O., Schepers, D., Galli, A., Aben, I., Frankenberg, C., Hartmann, J., Tran, H., Kuze, A., Aleks, G. K., Toon, G., Wunch, D., Wennberg, P., Deutscher, N., Griffith, D., Macatangay, R., Messerschmidt, J., Notholt, J., and Warneke, T.: Toward accurate $\mathrm{CO}_{2}$ and $\mathrm{CH}_{4}$ observations from GOSAT, Geophys. Res. Lett., 38, L14812, doi:10.1029/2011GL047888, 2011.

Crisp, D., Miller, C., and DeCola, P.: NASA Orbiting Carbon Observatory; measuring the column averaged carbon dioxide mole fraction from space, J. Appl. Remote Sens., 2, 023508, doi:10.1117/1.2898457, 2008.

Day, J. O., O’Dell, C. W., Pollock, R., Bruegge, C. J., Rider, D., Crisp, D., and Miller, C. E.: Preflight spectral calibration of the Orbiting Carbon Observatory, IEEE T. Geosci. Remote, 49, 2793-2801, doi:10.1109/TGRS.2011.2107745, 2011.

Engelstaedter, S., Tegan, I., and Washington, R.: North African dust emissions and transport, Earth-Sci. Rev., 79, 73-100, doi:10.1016/j.earscirev.2006.06.004, 2006.

Frankenberg, C.: OCO-2 IMAP-DOAS preprocessor algorithm theoretical basis document, available at: http://disc.sci.gsfc.nasa.gov/OCO-2/documentation/oco-2-v5/ IMAP_OCO2_ATBD_prelaunch.pdf, (last access: 1 March 2016), 2014.

Frankenberg, C., Platt, U., and Wagner, T.: Iterative maximum a posteriori (IMAP)-DOAS for retrieval of strongly absorbing trace gases: Model studies for $\mathrm{CH}_{4}$ and $\mathrm{CO}_{2}$ retrieval from near infrared spectra of SCIAMACHY onboard ENVISAT, Atmos. Chem. Phys., 5, 9-22, doi:10.5194/acp-5-9-2005, 2005.

Frey, R. A., Ackerman, S. A., Liu, Y., Strabala, K. I., Zhang, H., Key, J. R., and Wang, X.: Cloud detection with MODIS. Part I: Improvements in the MODIS cloud mask for collection 5, J. Atmos. Ocean Tech., 25, 1057-1072, doi:10.1175/2008JTECHA1052.1, 2008.

Gao, B., Yang, P., Han, W., Li, R.-R., and Wiscombe, W.: An algorithm using visible and $1.38-\mu \mathrm{m}$ channels to retrieve cirrus cloud reflectances from aircraft and satellite data, IEEE T. Geosci. Remote, 40, 1659-1668, doi:10.1109/TGRS.2002.802454, 2002.

Guerlet, S., Butz, A., Schepers, D., Basu, S., Hasekamp, O. P., Kuze, A., Yokota, T., Blavier, J., Deutscher, N. M., Griffith, D. W., Hase, F., Kyro, E., Morino, I., Sherlock, V., Sussmann, R., Galli, A., and Aben, I.: Impact of aerosol and thin cirrus on retrieving and validating $\mathrm{X}_{\mathrm{CO}_{2}}$ from GOSAT shortwave infrared measurements, J. Geophys. Res., 118, 4887-4905, doi:10.1002/jgrd.50332, 2013.

Hsu, N., Jeong, M.-J., Bettenhausen, C., Sayer, A., Hansell, R., Seftor, C., Huang, J., and Tsay, S.-C.: Enhanced Deep Blue aerosol retrieval algorithm: The second generation, J. Geophys. Res., 118, 9296-9315, doi:10.1002/jgrd.50712, 2013.

Kuze, A., Suto, H., Nakajima, M., and Hamazaki, T.: Thermal and near infrared sensor for carbon observation Fourier-transform spectrometer on the Greenhouse Gases Observing Satellite for greenhouse gases monitoring, Appl. Optics, 48, 6716-6733, 2009.

L'Ecuyer, T. and Jiang, J.: Touring the atmosphere aboard the ATrain, Phys. Today, 63, 36-41, doi:10.1063/1.3463626, 2010.

Lee, R. A. M., O’Dell, C. W., Wunch, D., Roehl, C., Osterman, G. B., Blavier, J.-F., Rosenberg, R., Chapsky, L., Frankenberg, C., Hunyadi-Lay, S. L., Fisher, B. M., Rider, D. M., Crisp, D., and
Pollock, R.: Preflight spectral calibration of the Orbiting Carbon Observatory 2, IEEE T. Geosci. Remote, submitted, 2016.

Liu, J., K., B., Lee, M., Henze, D., Bousserez, N., Brix, H., Collatz, G., Menemenlis, D., Ott, L., Pawson, S., Jones, D., and Nassar, R.: Carbon monitoring system flux estimation and attribution: impact of ACOS-GOSAT XCO2 sampling on the inference of terrestrial biospheric sources and sinks, Tellus B, 66, 22486, doi:10.3402/tellusb.v66.22486, 2014.

Maddux, B., Ackerman, S., and Platnick, S.: Viewing geometry dependencies in MODIS cloud products, J. Atmos. Ocean Tech., 27, 1519-1528, doi:10.1175/2010JTECHA1432.1, 2010.

Merrelli, A., Bennartz, R., O'Dell, C. W., and Taylor, T. E.: Estimating bias in the OCO-2 retrieval algorithm caused by 3-D radiation scattering from unresolved boundary layer clouds, Atmos. Meas. Tech., 8, 1641-1656, doi:10.5194/amt-8-1641-2015, 2015.

Miller, C., Crisp, D., DeCola, P., Olsen, S., Randerson, J., Michalak, A., Alkhaled, A., Rayner, P., Jacob, D., Suntharalingam, P., Jones, D., Denning, A., Nicholls, M., Doney, S., Pawson, S., Boesch, H., Connor, B., Fung, I., O'Brien, D., Salawitch, R., Sander, S., Sen, B., Tans, P., Toon, G., Wennberg, P., Wofsy, S., Yung, Y., and Law, R.: Precision requirements for space-based $\mathrm{X}_{\mathrm{CO}_{2}}$ data, J. Geophys. Res., 112, D10314, doi:10.1029/2006JD007659, 2007.

O'Brien, D. M., Polonsky, I., O'Dell, C., and Carheden, A.: Orbiting Carbon Observatory (OCO), Algorithm Theoretical Basis Document: The OCO simulator, Technical Report ISSN 0737-5352-85, Cooperative Institute for Research in the Atmosphere, Colorado State University, Fort Collins, CO, USA, available at: ftp://ftp.cira.colostate.edu/ftp/TTaylor/publications/ 20090813_OCO_simulator.pdf (last access: 4 March 2016), 2009.

O'Dell, C., Taylor, T. E., and Eldering, A.: OCO-2 Oxygen-A band cloud screening algorithm (ABO2) algorithm theoretical basis document, Tech. Rep. D-81520, Jet Propulsion Laboratory, available at: http://disc.sci.gsfc.nasa.gov/OCO-2/documentation/ oco-2-v5/oco2_abo2_atbd_prelaunch_4.pdf, (last access: 1 March 2016), 2014.

O’Dell, C. W., Day, J. O., Pollock, R., Bruegge, C. J., O’Brien, D. M., Castano, R., Tkatcheva, I., Miller, C. E., and Crisp, D.: Preflight radiometric calibration of the Orbiting Carbon Observatory, IEEE T. Geosci. Remote, 49, 2438-2447, doi:10.1109/TGRS.2010.2090887, 2011.

O’Dell, C. W., Connor, B., Bösch, H., O’Brien, D., Frankenberg, C., Castano, R., Christi, M., Eldering, D., Fisher, B., Gunson, M., McDuffie, J., Miller, C. E., Natraj, V., Oyafuso, F., Polonsky, I., Smyth, M., Taylor, T., Toon, G. C., Wennberg, P. O., and Wunch, D.: The ACOS CO2 retrieval algorithm - Part 1: Description and validation against synthetic observations, Atmos. Meas. Tech., 5, 99-121, doi:10.5194/amt-5-99-2012, 2012.

Rodgers, C. D.: Inverse Methods For Atmospheric Sounding: Theory and Practice, World Scientific Publishing Co. Pte. Ltd., Singapore, 2000.

Rosenberg, R., Maxwell, S., Johnson, B. C., Chapsky, L., Lee, R. A., and Pollock, R.: Preflight radiometric calibration of Orbiting Carbon Observatory-2, IEEE T. Geosci. Remote, submitted, 2016.

Savtchenko, A., Kummerer, A., Smith, P., Gopalan, A., Kempler, S., and Leptoukh, G.: A-Train Data Depot - Bringing atmo- 
spheric measurements together, IEEE T. Geosci. Remote, 46, 2788-2795, doi:10.1109/TGRS.2008.917600, 2008.

Seidel, F. C. and Popp, C.: Critical surface albedo and its implications to aerosol remote sensing, Atmos. Meas. Tech., 5, 16531665, doi:10.5194/amt-5-1653-2012, 2012.

Stephens, G. L., Vane, D. G., Boain, R. J., Mace, G. G., Sassen, K., Wang, Z., Illingworth, A. J., O’Connor, E. J., Rossow, W. B., Durden, S. L., Miller, S. D., Austin, R. T., Benedetti, A., and Mitrescu, C.: The Cloudsat mission and the A-train: A new dimension of space-based observations of clouds and precipitation, B. Am. Meteorol. Soc., 83, 1771-1790, 2002.

Taylor, T. E. and O'Brien, D. M.: A neural network cloud screening algorithm. Part I: a synthetic case over land surfaces using micro-windows in $\mathrm{O}_{2}$ and $\mathrm{CO}_{2}$ near infrared absorption bands with nadir viewing, J. Appl. Remote Sens., 3, 033548, doi:10.1117/1.3239515, 2009.

Taylor, T. E., O’Dell, C. W., O'Brien, D. M., Kikuchi, N., Yokota, T., Nakajima, T. Y., Ishida, H., Crisp, D., and Nakajima, T.: Comparison of cloud-screening methods applied to GOSAT near-infrared spectra, IEEE T. Geosci. Remote, 50, 295-309, doi:10.1109/TGRS.2011.2160270, 2012.

Vaughn, M. A., Powell, K. A., Winker, D. M., Hostetler, C. A., Kuehn, R. E., Hunt, W. H., Getzewichand, B. J., Young, S. A., Liu, Z., and McGill, M. J.: Fully automated detection of cloud and aerosol layers in the CALIPSO lidar measurements, J. Atmos. Ocean Tech., 26, 2034-2050, doi:10.1175/2009JTECHA1228.1, 2009.

Winker, D. M., Hunt, W. H., and McGill, M. J.: Initial performance assesement of CALIOP, Geophys. Res. Lett., 34, L19803, doi:10.1029/2007GL030135, 2007.

Winker, D. M., Pelon J., Coakley Jr., J., Ackerman, S., Charlson, R., Colarco, P., Flamant, P., Fu, Q., Hoff, R., Kittaka, C., Kubar, T., Treut, H. L., McCormick, M., Megie, G., Poole, L., Powell, K., Trepte, C., Vaughan, M., and Wielicki, B.: The CALIPSO mission, B. Am. Meteorol. Soc., 91, 1211-1229, doi:10.1175/2010BAMS3009.1, 2010.

Wunch, D., Toon, G. C., Wennberg, P. O., Wofsy, S. C., Stephens, B. B., Fischer, M. L., Uchino, O., Abshire, J. B., Bernath, P., Biraud, S. C., Blavier, J.-F. L., Boone, C., Bowman, K. P., Browell, E. V., Campos, T., Connor, B. J., Daube, B. C., Deutscher, N. M., Diao, M., Elkins, J. W., Gerbig, C., Gottlieb, E., Griffith, D. W. T., Hurst, D. F., Jiménez, R., Keppel-Aleks, G., Kort, E. A., Macatangay, R., Machida, T., Matsueda, H., Moore, F., Morino, I., Park, S., Robinson, J., Roehl, C. M., Sawa, Y., Sherlock, V., Sweeney, C., Tanaka, T., and Zondlo, M. A.: Calibration of the Total Carbon Column Observing Network using aircraft profile data, Atmos. Meas. Tech., 3, 1351-1362, doi:10.5194/amt3-1351-2010, 2010.
Wunch, D., Wennberg, P. O., Toon, G. C., Connor, B. J., Fisher, B., Osterman, G. B., Frankenberg, C., Mandrake, L., O’Dell, C., Ahonen, P., Biraud, S. C., Castano, R., Cressie, N., Crisp, D., Deutscher, N. M., Eldering, A., Fisher, M. L., Griffith, D. W. T., Gunson, M., Heikkinen, P., Keppel-Aleks, G., Kyrö, E., Lindenmaier, R., Macatangay, R., Mendonca, J., Messerschmidt, J., Miller, C. E., Morino, I., Notholt, J., Oyafuso, F. A., Rettinger, M., Robinson, J., Roehl, C. M., Salawitch, R. J., Sherlock, V., Strong, K., Sussmann, R., Tanaka, T., Thompson, D. R., Uchino, O., Warneke, T., and Wofsy, S. C.: A method for evaluating bias in global measurements of $\mathrm{CO}_{2}$ total columns from space, Atmos. Chem. Phys., 11, 12317-12337, doi:10.5194/acp11-12317-2011, 2011.

Wunch, D., Osterman, G., Fisher, B., Naylor, B., Roehl, C., O’Dell, C., Viatte, C., Eldering, A., and Wennberg, P.: Target-mode measurements from the Orbiting Carbon Observatory (OCO-2), in preparation, 2016.

Xiong, X., Chiang, K., Sun, J., Barnes, W., Guenther, B., and Salomonson, V.: NASA EOS Terra and Aqua MODIS on-orbit performance, Adv. Space Res., 43, 413-422, doi:10.1016/j.asr.2008.04.008, 2009.

Yoshida, Y., Eguchi, N., Ota, Y., Kikuchi, N., Nobuta, K., Aoki, T., and Yokota, T.: $\mathrm{CO}_{2}$ and $\mathrm{CH}_{4}$ column amounts retrieval from GOSAT TANSO-FTS SWIR, Algorithm Theoretical Basis Document, NIES GOSAT Project, 2010.

Yoshida, Y., Ota, Y., Eguchi, N., Kikuchi, N., Nobuta, K., Tran, H., Morino, I., and Yokota, T.: Retrieval algorithm for $\mathrm{CO}_{2}$ and $\mathrm{CH}_{4}$ column abundances from short-wavelength infrared spectral observations by the Greenhouse gases observing satellite, Atmos. Meas. Tech., 4, 717734, doi:10.5194/amt-4-717-2011, 2011. 